\title{
Climate Dynamics \\ Impact of Euro-Atlantic blocking patterns in Iberia precipitation using a novel high resolution dataset \\ --Manuscript Draft--
}

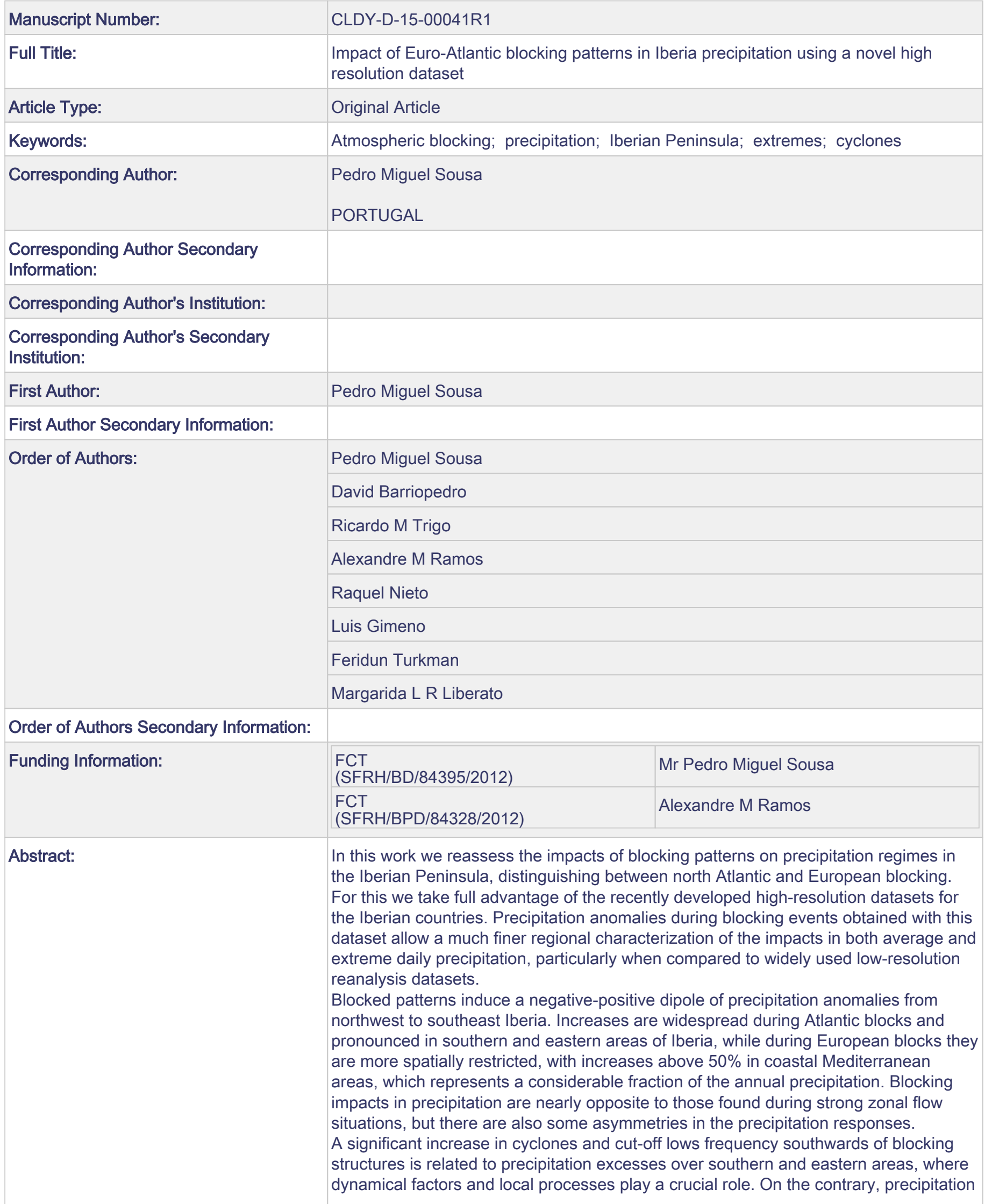


deficits in northwest lberia during blocking episodes are better explained by a reduction in north Atlantic frontal activity and simultaneous decreases in large-scale moisture advection towards northern Iberia.

We show that these anomalies during blocking result from changes in precipitation amount rather than from increases in rainy days, pointing to more extreme rainfall regimes, particularly in southeastern Iberia. Finally, an Extreme Value Analysis was performed, fitting Generalized Pareto Distributions to precipitation extremes. Results show that the different extreme precipitation regimes of northwest and Mediterranean regions are partially determined by opposite anomalies of the zonal flow. Thus, heavy precipitation events in Mediterranean areas are usually short-lived and frequently associated with blocking conditions, while in northwest lberia the total accumulations during rainfall episodes are more important for triggering extreme events and they are mainly related to strong westerly flows. 
Impact of Euro-Atlantic blocking patterns in Iberia precipitation using a novel high resolution dataset

4

\section{Pedro M. Sousa ${ }^{1}$, David Barriopedro ${ }^{2,3}$, Ricardo M. Trigo ${ }^{1}$,}

\section{Alexandre M. Ramos ${ }^{1}$, Raquel Nieto ${ }^{4}$, Luis Gimeno ${ }^{4}$, Feridun Turkman $^{5}$, Margarida L.R. Liberato ${ }^{1,6}$}




\section{Abstract}

In this work we reassess the impacts of blocking patterns on precipitation regimes in the Iberian Peninsula, distinguishing between north Atlantic and European blocking. For this we take full advantage of the recently developed high-resolution datasets for the Iberian countries. Precipitation anomalies during blocking events obtained with this dataset allow a much finer regional characterization of the impacts in both average and extreme daily precipitation, particularly when compared to widely used lowresolution reanalysis datasets.

Blocked patterns induce a negative-positive dipole of precipitation anomalies from northwest to southeast Iberia. Increases are widespread during Atlantic blocks and pronounced in southern and eastern areas of Iberia, while during European blocks they are more spatially restricted, with increases above $50 \%$ in coastal Mediterranean areas, which represents a considerable fraction of the annual precipitation. Blocking impacts in precipitation are nearly opposite to those found during strong zonal flow situations, but there are also some asymmetries in the precipitation responses.

A significant increase in cyclones and cut-off lows frequency southwards of blocking structures is related to precipitation excesses over southern and eastern areas, where dynamical factors and local processes play a crucial role. On the contrary, precipitation deficits in northwest Iberia during blocking episodes are better explained by a reduction in north Atlantic frontal activity and simultaneous decreases in large-scale moisture advection towards northern Iberia.

We show that these anomalies during blocking result from changes in precipitation amount rather than from increases in rainy days, pointing to more extreme rainfall regimes, particularly in southeastern Iberia. Finally, an Extreme Value Analysis was performed, fitting Generalized Pareto Distributions to precipitation extremes. Results show that the different extreme precipitation regimes of northwest and Mediterranean regions are partially determined by opposite anomalies of the zonal flow. Thus, heavy precipitation events in Mediterranean areas are usually short-lived and frequently associated with blocking conditions, while in northwest Iberia the total accumulations during rainfall episodes are more important for triggering extreme events and they are mainly related to strong westerly flows.

Keywords: atmospheric blocking; precipitation; Iberian Peninsula; extremes; cyclones

\section{Introduction}

The climate of Europe is controlled to a large extent by the usual sequence of low-pressure systems travelling from the west and associated with the jet stream. These mid-latitude cyclones leave their fingerprint on spells of varying precipitation amount, alternating with dry periods that range from weekly to monthly scales. With the advent of upper level observations in the wake of the WWII, it was found that this pattern of predominantly zonal circulation is often disrupted by a temporary change to a situation of strong meridional flow [e.g., Rex (1950a,b)]. This meridional component favors the formation of quasistationary anticyclones at high latitudes, coined as blocking highs [Rex (1950a,b)], which are often accompanied by low-pressure areas at lower latitudes (Treidl et al., 1981).

The influence of blocking systems on the climate of mid-latitudes is well known. The first climate assessments of the impact of blocking were based on very few cases (e.g. Rex 1951), or on particular anomalous seasons (e.g. Quiroz 1984). More recently, the longer reanalysis datasets have been used to characterize blocking (e.g., Barriopedro et al., 2006, 2010; Croci-Maspoli et al., 2007; Davini et al. 2012) and their associated impacts (e.g., Trigo et al., 2004; Masato et al. 2012), including extreme events (e.g., Sillmann and Croci-Maspoli 2009a; Buehler et al. 2011), such as the drought events in the Iberian Peninsula (IP) during 2004-2005 (García-Herrera et al., 2007) and 2011-2012 (Trigo et al., 2013), or the more recent outstanding heatwaves in the Euro-Russian area (Barriopedro et al., 2011; Ruti et al., 2014). 
The specific role of atmospheric blocking on precipitation regimes has been widely studied, although there is some tendency to focus on the climate of the area more directly affected by the anomalous stationary ridge. In this restricted spatial context, blocking occurrence causes precipitation scarceness. Nevertheless, blocking episodes may also increase precipitation in remote regions, since storm tracks tend to be deflected north and south of the blocking systems. Trigo et al. (2004) found that blocking episodes in the Euro-Atlantic sector reduce the precipitation rate at higher latitudes, and increase it in southernmost areas of Europe. In addition, blocking can be favorable for strangling upper level cold air pools (usually referred as cut-off lows), which may produce severe weather and flooding (Nieto et al., 2007). Cut-off lows are more frequent in spring and summer seasons, and in mid and low latitudes, with the European sector being a preferred sector of occurrence. In particular, Nieto et al. (2007) has shown that the southern flank of blocking systems is a favorable location for cut-off occurrence. This is crucial for the climate of the IP, where some of the most torrential rainfall episodes can arise from relatively small-scaled lowpressure systems. Some examples of cut-off low systems occurring under large-scale blocked conditions are the exceptional rainfall event in the Lisbon area in 18 February 2008 (Fragoso et al., 2010), or the October 2000 torrential precipitation event in eastern Spain (Homar et al.; 2002). In addition, and particularly during late summer and early autumn, cut-off lows can trigger Mesoscale Convective Systems affecting the eastern coast of Spain and the Balearic Islands (García-Herrera et al., 2005).

Within the context of blocking-related impacts, it is imperative to distinguish the disruption of the prevailing westerly circumpolar flow by a blocking episode from the strengthening of the North Atlantic ridge at lower latitudes $\left(40-50^{\circ} \mathrm{N}\right.$ - sometimes called low-latitude blocking), which is frequently linked with sub-tropical high pressure systems. Santos et al. $(2008,2009)$ have studied the latter, and linked such events with the occurrence of severe droughts in the IP, particularly in the western half, since these patterns prevent storms from reaching that region. On the contrary, closed and persistent blocking systems located at higher latitudes leave a margin for the occurrence of synoptic eddies at lower latitudes (e.g., Pfhal, 2014). More specifically, the blocking pattern induces a shift of the usual storm-track paths that can interact with the sub-tropical jet stream, enhancing large-scale ascending motions, instability and the development of severe precipitation events (Toreti et al., 2010). Thus, unlike strong ridges, which tend to deprive the IP of rains, blocking episodes can promote either dry periods or wet spells therein, depending on the location of the blocking pattern.

The strong spatial and temporal variability of precipitation regimes in the IP, with the relatively high frequency of blocking patterns (Barriopedro et al., 2006; Woolings et al., 2010) and cut-off-lows (Nieto et al., 2007) in western Europe converts the IP in an excellent "laboratory" to evaluate the impacts of blocking episodes. However, blocking-induced low pressure systems may produce very distinct signatures in precipitation at the regional scale. This underlines the need of high-resolution precipitation datasets to obtain a more comprehensive assessment on the impacts of blocking episodes on the IP precipitation regimes. Previous studies have used gridded precipitation datasets with poor spatial horizontal resolutions to address blocking effects on precipitation (e.g. Trigo et al. 2004), thus possibly losing crucial spatial details. Additionally, Trigo et al. (2004) found that the blocking signals in precipitation are relatively unconnected from those in precipitable water, which are rather controlled by blocking-induced temperature anomalies. This fact suggests that the precipitation anomalies in IP during blocking situations are mainly driven by dynamical factors, such as higher-than-usual cyclonic activity, albeit the importance of thermodynamic factors in the precipitation responses to blocking cannot be disregarded. This fact stresses the need to explore the blocking influence on cyclone paths, and cut-off lows in the region.

In this study we perform a reassessment of blocking impacts on precipitation using the recently developed Iberian high-resolution gridded precipitation datasets (Belo-Pereira et al., 2011; Herrera et al., 2010). Moreover, we assess in detail how precipitation anomalies and associated atmospheric circulation change with respect to the specific location of the blocking high patterns. This spatial dependence may be crucial to determine the local impacts and extremeness of precipitating systems like cyclones and cut-off lows. Finally, we also explore the relationship between blocking and the occurrence of extreme precipitation. In 
summary, the main objectives of this work are: 1) to examine blocking impacts, in terms of precipitation anomalies and physical forcings (instability and moisture fluxes), distinguishing the sector of blocking occurrence; 2) to identify changes in cyclonic activity and cut-off lows frequency during blocking episodes; 3) to perform an Extreme Values Analysis for Iberian precipitation during blocking episodes.

This work is structured as follows. In Section 2, the data used in this work is described, and a brief overview of the blocking climatology in the target domain is presented. In Section 3, we analyze the impacts of different weather patterns (namely blocked and strong zonal flow) on the precipitation regimes, and compare them when using datasets of different spatial resolution. The synoptic patterns and forcings that promote these impacts are described in Section 4. An Extreme Value Analysis is performed in Section 5, and finally, in Section 6, the main results of this work are discussed.

\section{Data}

\subsection{Reanalysis data}

We have used the following datasets for the purposes of our analysis:

a) The recently developed high-resolution precipitation datasets for Portugal (PT02 - Belo-Pereira et al., 2011), and Spain (SPAIN02 - Herrera et al., 2010), which have a horizontal resolution of $0.2^{\circ} \times 0.2^{\circ}$ and have been combined in a single dataset (IBERIA02) for the years spanning from 1950 until 2007. The average number of stations used by both datasets is very large (although not constant during the period), allowing its application for both climatological studies (e.g. Ramos et al., 2014), and characterization of extreme precipitation events (Ramos et al., 2015).

b) The dataset from the NCEP/NCAR reanalysis (Kalnay et al., 1996) for the 1948-2007 period, at a $2.5^{\circ} \times 2.5^{\circ}$ horizontal resolution. The variables explicitly considered were: daily fields of $500 \mathrm{hPa}$ geopotential height (Z500) and Lifted Index (LI) - the latter is an instability index defined by the temperature difference between an air parcel lifted adiabatically and the temperature of the environment at Z500. Furthermore, we made use of several fields from the NCEP/NCAR data to compute the following data: 1) a catalogue of blocking events (Barriopedro et al., 2010); 2) a catalogue of cut-off lows (COL - Nieto et al., 2005); 3) Integrated Water Vapor Transport between $1000 \mathrm{hPa}$ and $300 \mathrm{hPa}$ (IVT - Ramos et al., 2015); 4) a catalogue of cyclones for the northern hemisphere obtained by using the methodology described in Trigo (2006). These datasets will be employed to explore the blocking signatures in precipitation regimes and interpret these responses in terms of dynamical (cyclones, COLs) and thermodynamical (IVT, LI) processes. The particular characteristics of the blocking catalogue are explored in more detail in the following sub-section.

\subsection{Blocking index catalogue}

The catalogue of blocked days was developed by Barriopedro et al. (2010) by using daily Z500 data on a $2.5^{\circ} \times 2.5^{\circ}$ grid. The method attempts to reconcile previous blocking definitions, and to minimize the discrepancies between them. Thus, blocks are considered from a complementary viewpoint as Z500 anomalous patterns, which are capable of reversing the meridional jet-based Z500 gradient. This combined blocking detection method also avoids some unrealistic criteria or critical parameters that were implicit to previous methodologies and improves the blocking detection efficiency. Daily blocks are identified as contiguous 2-D spatial signatures, corresponding to Z500 anomalies above a given threshold (one-standard deviation of the daily Z500 anomaly distribution at extratropical latitudes). The method also requires these blocked areas to be associated with meridional Z500 gradient reversals around a reference latitude representative of the jet stream. For each longitude, the reference latitude is defined as 
the latitude with maximum variance in the 5-day high-pass filtered Z500 field. The variation of these variables within the year is considered, in order to accommodate the seasonal cycle. A tracking algorithm is also implemented to follow the day-to-day evolution of blocking patterns. Finally, to account for the typical scales of the block and its spatio-temporal evolution, thresholds for minimum 2-D extension $\left(2 \cdot 10^{6} \mathrm{~km}^{2}\right)$, minimum temporal persistence (5 days), and a fraction of overlapping between successive daily blocks (50\%) are required.

In this study, we only considered daily blocking patterns for which the maximum Z500 anomaly is located between $45^{\circ} \mathrm{N}$ and $70^{\circ} \mathrm{N}$, and these locations will hereafter be called blocking centers. We must stress that this definition has the purpose to enable an objective separation in blocking sectors by reducing the large-scale of the blocking pattern to a single gridpoint that is representative of the weather system, as the specific location of a blocking center plays a major role in defining the synoptic circulation of a much wider region. Thus, two main sectors are defined: the Atlantic sector (ATL) which includes all blocking centers located in $30-0^{\circ} \mathrm{W}$, and the European sector (EUR), spanning $0-30^{\circ}$ E. This regional classification is justified from previous works that have explored the relationship between blocking and the main modes of variability of the atmospheric circulation (e.g., Barriopedro et al. 2006; Scherrer et al. 2006). These studies have reported a tight link between blocking activity and the centers of variability of the leading modes in the Euro-Atlantic sector, with the North Atlantic Oscillation (NAO) and the Scandinavian Pattern (SCAN) explaining most of the variability of ATL and EUR blocking, respectively. ATL and EUR blocking have also very distinct signals in European precipitation and temperature (e.g., Masato et al. 2012). Figure 1 (top) depicts the annual mean frequency of blocking center locations in each gridpoint $\left(2.5^{\circ} \times 2.5^{\circ}\right)$, as well as the seasonal frequency of blocking centers for each considered sector (bottom). It must remain clear that the main goal of classifying blocks into ATL and EUR types is to assess how the precipitation responses depend on the blocking location. Thus, this distinction between ATL and EUR blocks is purely based on their location, and does not necessarily involve different physical/dynamical processes in their lifecycles.

Before evaluating the regional impacts of blocking on the IP precipitation, it is important to briefly characterize the atmospheric circulation signatures associated with regional blocking occurrence. Figure 2 shows the composite of Z500 anomalies for blocking days in each sector and season. For both sectors, Z500 positive anomalies are larger in the cold seasons than in the warm seasons. The largest anomalies are associated with ATL blocking. In this region, summer blocks display a northward extension of subtropical wave-breaking systems near the Azores high. Regional blocking is also associated to negative Z500 anomalies in some of the surrounding areas, being more evident during ATL blocks and in colder seasons, but less pronounced than the positive ones. These negative anomalies display different intensity and location for ATL and EUR blocks, which suggest different impacts on precipitation, thus supporting the classification in blocking sectors adopted herein. Note that some blocking events may contribute to the composites of both sectors, since ATL blocks tend to evolve eastwards towards Europe throughout their lifecycle (Croci-Maspolli et al., 2007; Barriopedro et al. 2010). This is supported by similar composites (see Supplementary Material - S1) performed for blocking subsectors of $15^{\circ}$ longitudinal extension within the ATL and EUR regions.

\section{Seasonal impacts of blocking in Iberian precipitation}

With the aim of evaluating the impacts of blocking on the IP precipitation, seasonal composites of daily precipitation anomalies were calculated for days with blocking centers in each sector. For this purpose, daily anomaly series of precipitation in each gridpoint were computed, and then composited for blocking days of each season and sector. We opted to present the relative anomalies in the composites (in percentage relative to the climatological seasonal precipitation during 1950-2007), as seen in Figure 3. Gridpoints where the climatological seasonal mean total precipitation is below $50 \mathrm{~mm}$ were discarded, since relative anomalies in dry areas may be misleading. This process excludes dryer regions in 
southern/central IP, where summer rainfall is usually scarce (Belo-Pereira et al., 2011), and the relevance of high anomalies would be doubtful. A two-sample Smirnov-Kolmogorov test (hereafter KStest) was applied to assess the statistical significance of these anomalies (Wilks, 2011).

The composites presented in Fig. 3 show that, with the exception of summer, the seasonal patterns of regional blocking signals in precipitation are reasonably coherent throughout the year, particularly for ATL blocks. The NCEP/NCAR reanalysis composites show a consistent positive precipitation anomaly in the Mediterranean coast associated with blocking occurrence in both sectors. In particular, during winter, the NCEP/NCAR reanalysis displays very minor differences between the impacts of ATL and EUR blocks. However, the high-resolution IBERIA02 dataset reveals specific regional details in these patterns and clear differences between ATL and EUR blocks. For example, significant negative precipitation anomalies are found in northwestern regions of the IP that cannot be clearly identified using the lowresolution dataset. In summer, the NCEP/NCAR reanalysis displays a SW-NE gradient response in precipitation anomalies that is absent in the high resolution dataset. We must bear in mind that most of IP registers low mean precipitation values during these months and, consequently, one should refrain from over-emphasizing summer anomalies.

Regarding the different impacts that arise from different blocking locations, it is found that for most of the year (with the exception made for spring), ATL blocks are associated with increased precipitation over wide areas of the IP, while EUR blocks tend to bring more localized positive anomalies, particularly in coastal Mediterranean strips. For instance, during autumn, ATL blocks lead to above average precipitation in almost the entire peninsula. Taking this example, once again, the impact of the different resolutions from the datasets appears very clear, as EUR blocking composite for the NCEP/NCAR dataset clearly miss most of the positive autumn precipitation anomalies that are depicted by the corresponding IBERIA02 composite.

Taking into account the tendency for eastward blocking migration mentioned above, we have also computed the precipitation anomaly composites occurring in the previous five days to EUR blocks. These composites show a quite similar pattern (see Supplementary Material - S2) to the one found for ATL blocking, thus confirming that the transition from the ATL to the EUR precipitation composites partially reflects the transient responses to an eastward blocking migration and hence, that the precipitation responses to blocking depend on the blocking location.

With the aim of summarizing the different impacts of regional blocking, we computed annual composites of daily precipitation anomalies for each blocking sector. Furthermore, to better interpret the blocking signatures we compared them with the corresponding composites obtained for days characterized by strong zonal flow, which represents a large-scale atmospheric pattern with nearly opposite anomalies to those associated with blocking. This procedure allows assessing the linear response in precipitation to opposite zonal flow regimes. For this purpose, we followed very simple criteria described in Trigo et al. (2004) to classify strong zonal flow days in the Atlantic and European sectors: 1) a given longitude is affected by strong zonal flow conditions if the meridional mid-latitude Z500 gradients exceed several empirical thresholds (see Trigo et al. 2004 for further details); 2) the entire sector is considered to be in strong zonal flow configuration if at least three adjacent longitudes satisfy 1 ). The KStest was applied to assess the statistical significance of these anomalies.

The annual composites of daily precipitation anomalies for regional blocking and strong zonal flow conditions are shown in Figure 4. The existence of a negative-positive dipole in precipitation anomalies under blocking action is again evidenced at the annual scale. For both blocking sectors, the positive precipitation anomalies found in eastern and southern coastal areas are considerably wider in spatial extension and larger in amplitude than the negative anomalies found in northwestern IP, which are essentially restricted to ATL blocks. During strong zonal episodes there is also a tendency for a northwest-southeast dipole in precipitation anomalies, but with the opposite signals to those found during blocking conditions. Strong westerly flows are related with below average precipitation in southern and 
eastern IP, and with near-normal or non-significant precipitation excess in the northwest. As a consequence, the differences between blocked and zonal conditions depict an even more contrasting dipole, which reflects the large relevance that blocking episodes wield on rainfall regimes in southern and eastern regions of Iberia, where we once again stress that mean annual rainfall totals are much lower than for northwestern sectors (Belo-Pereira et al., 2011).

As stated above, the high-resolution precipitation data set allows identifying important differences between the regional and local precipitation responses associated with ATL and EUR blocks that otherwise would be missed in a coarser grid. Thus, during ATL blocks positive anomalies cover a wider area than that affected by EUR blocks, and also the locations of the largest anomalies are different depending on the considered sector. In particular, during EUR blocks there is a particular emphasis on the coastal strip of eastern Spain, while under ATL blocks the highest anomalies are found further south in eastern Spain, and also in southernmost areas of the IP and the Gibraltar area. On the other hand, a sharp northwest-southeast gradient is found for ATL blocks, while EUR blocks show a less pronounced gradient, and a slight northward shift of the associated maximum of precipitation, as compared to ATL blocks. Also, the deficit of precipitation in northwest IP is clearly identifiable for blocking located in the ATL sector, but it does not reach the 5\% statistical significance level in the EUR composite. The same regional differences are observed in the blocking minus strong zonal flow composite difference.

Another interesting difference between the ATL and EUR composites is their different linear response to blocked and zonal flows. Thus, the precipitation response to opposite anomalous conditions in the westerly flow over EUR is largely linear, while for the ATL sector there are important asymmetries. It should be noticed that part of these results may be due to a larger difference between the frequencies of blocked and zonal days for ATL when compared to EUR. In particular, the precipitation signals over eastern IP during ATL blocks are much larger than those observed during strong zonal flow conditions. This implies that the precipitation regimes of these areas are particularly sensitive to blocked conditions. Such asymmetric responses to circulation anomalies in the ATL sector are much more difficult to identify when relying on composites obtained using the NCEP/NCAR low-resolution dataset, once again reinforcing the convenience of the high-resolution dataset.

The impact of blocking events in the precipitation regimes of the eastern and southern sectors of IP (Fig. 4) coupled with the considerably lower climatological precipitation values observed in these regions necessarily imply a considerable contribution of blocking episodes on total yearly precipitation therein (solid lines, upper panels Fig. 5), which exceeds 10\% in eastern areas of the IP. We were also interested in checking if the precipitation anomalies during blocking patterns are derived from an equivalent change in the number of rainy days, or from changes in the precipitation amount during precipitating days. To address this question, we computed regional blocking composites of the anomalous number of days with total precipitation above $1 \mathrm{~mm}$. The results (Fig.5, shaded) indicate a large decrease in the number of rainy days over the northwestern half IP and much smaller changes elsewhere. The pronounced drop of rainy days in northwestern IP (in some areas above 20\%) only impinges a slight decrease in total precipitation (Fig. 4). We argue that this result could be due to blocking mainly inducing light precipitating days in the NW sector of IP, thus leading to small net changes. The decrease in the number of rainy days during blocking situations also affects other large portions of the IP, including regions where the precipitation composites showed significant increases in total precipitation. This suggests that the precipitation responses to blocking are largely attributable to changing rates of precipitation rather than to the number of precipitating days, especially in southeastern IP. Naturally, this also involves a higher frequency of intense or torrential precipitation days during blocked patterns in these regions, as it will be discussed further ahead. 


\section{Synoptic forcing}

313 Once the impacts of regional anomalous zonal flow conditions on IP precipitation regimes are well characterized, it is important to understand the processes that drive them at the synoptic scale. As shown in previous works, blocking occurrence induces positive precipitation anomalies in several areas of southern Europe, but it does not promote higher values of precipitable water in the same areas (e.g. Trigo et al., 2004). Thus, it is mandatory to distinguish processes that enhance moisture availability from those that provide the favorable conditions for water condensation. For this purpose, we computed anomalous composites (for blocked and strong zonal flow situations) of Z500, LI, and IVT (and the corresponding mean horizontal transport of IVT). In this way, we were able to compare the distribution of moisture fluxes (throughout the use of the IVT) and simultaneously the anomalies in instability (LI). The former is related to moisture availability for precipitation and the latter measures whether the environmental conditions are prone to enhance condensation of water vapor. The composites have been performed for blocked and zonal days, and their difference, as depicted in Figure 6.

The composites of Fig. 6 show that during strong zonal conditions there is a corridor of high moisture content transport extending towards the British Isles and affecting northwestern IP. This moist corridor is zonally elongated towards central Europe during strong zonal flow conditions over EUR, as compared to those occurring in ATL. Blocking patterns efficiently obstruct these moisture fluxes, which is in good agreement with the rainfall reductions observed in NW IP during blocking patterns, but not with the precipitation increases in southeastern IP. However, areas of positive LI anomalies are found in the IP during blocking episodes, with a dependence on the considered sector. Thus, atmospheric instability tends to be reinforced in western (eastern) IP during ATL (EUR) blocking days, in good agreement with the precipitation increases obtained in the previous section over southern (eastern) IP. Moreover, the difference between blocked and zonal flow composites shows a large increase in atmospheric instability over IP when we shift from zonal to blocked flows, despite their common reduction in moisture content at higher latitudes. This suggests that moisture availability is not a major limiting factor to explain the precipitation responses to anomalous zonal flow conditions over most of the IP. In fact, these composites show that the positive precipitation anomalies in south and eastern IP during blocking episodes are related with the increment of atmospheric instability in the target areas.

Additionally, we would like to explore whether the changes in moisture content and instability are triggered by specific weather systems. Trigo et al. (2004) already discussed the important role played by the southward deflection of the storm-tracks in the European precipitation responses to blocking episodes. Thus, taking into account the main synoptic patterns that trigger precipitation events in the IP, we next explore changes in their frequency during blocking and strong zonal flow episodes for each considered sector. In this regard, we herein distinguish between near-surface cyclones and upper-level low-pressure systems such as COLs, both causing negative Z500 anomalies (as those found over the IP in the blocking minus strong zonal flow composites of Fig. 6). To achieve this, we first looked at the climatological frequency of cyclones and COL in the Euro-Atlantic area, as presented in the top panels of Figures 7 and 8, respectively. The results reflect some well-known facts: 1) the North Atlantic is a preferred region for storm-tracks, with northwestern IP being commonly affected by them (Fig. 7); 2) the Mediterranean basin (and the IP in particular) are the regions in the Euro-Atlantic sector where COL activity is more frequent throughout the year (Fig. 8). We next check the amplitude and significance of eventual changes in their frequency (as compared to climatology) during blocking episodes for both the ATL and EUR sectors. We also explore if there is an agreement between cyclonic and COL blocking-related tracks and the already mentioned increases in atmospheric instability during these events.

The anomalies in cyclone activity (non-stationary near-surface systems) show a clear increase in most areas close to the IP during ATL blocks (Figure 7, middle left), in contrast with a sharp decrease in the UK, where cyclonic activity is almost non-existent during blocking patterns. For EUR blocks (Fig. 7, middle right) the cyclone frequency decrease is shifted eastwards (over the Scandinavia region), in good 
is predominantly non-significant. Note that despite the cyclone increase over the IP there is also a reduction in moisture fluxes to the north of the IP during blocking conditions (Fig. 6), which may explain the decrease in precipitation found in NW IP. In this regard, it must also be reminded that a large fraction of the precipitation that occurs in this region is related to frontal systems that are linked to cyclone centers located at higher latitudes (Trigo et al., 2004) and whose frequency is strongly reduced during blocking situations. This is supported by the ATL blocking composites of Fig. 6 and 7, which show that the maximum decrease in cyclonic activity occurs to the north of the corresponding decrease in moisture content. Thus, the precipitation deficits in NW IP during ATL blocks can be attributed to a decrease on the frequency of efficient Atlantic low-pressure systems affecting high latitudes (and the subsequent decrease in moisture fluxes in the vicinity of northwest Iberia).

Concerning changes in COLs activity, results show a significant increase around the Iberian Peninsula domain during ATL blocks (over 150\% in some areas) as presented in Figure 8. There is also an increase during EUR blocks, but displaced towards Eastern Europe, although still appreciable in eastern IP $(\sim 50 \%)$. The increase in COL and transient cyclones activity during ATL blocks is in fair agreement with the increase found in precipitation and atmospheric instability anomalies in southern IP. Regarding the responses found during EUR blocks, there is a slight decrease in cyclonic activity close to northeastern Iberia (Fig. 7), contrasting with a small increase of COL activity in the Mediterranean coast of the IP (Fig. 8). This fact suggests that the initial stages of COLs - corresponding to troughs located over the region which later develop and mature into COLs towards the east- may be the main cause for the significant increases in atmospheric instability and precipitation in the area.

Furthermore, the analysis of Fig.7 (bottom panel) shows that in the IP region the responses in cyclone frequency to strong zonal flows are similar for the two sectors (both negative). This fact shows that the different precipitation responses to ATL and EUR zonal flows (see Fig. 4) are likely not related to changes in cyclone paths. On the contrary, the areas of higher reduction in COLs shift eastwards from ATL to EUR zonal flows (Fig. 8), apparently in better agreement with the respective regions of negative precipitation anomalies (Fig. 4). Still, we must bear in mind that both cyclones and COLs analyses were performed on coarser grids when compared to the high-resolution precipitation dataset, thus losing some information about the dependence of the precipitation responses on small changes in the location of these synoptic systems.

\section{Extreme value analysis}

As stated in the introduction, several areas of the IP are often affected by episodes of torrential precipitation, with significant contributions to seasonal totals, and important socio-economic impacts. This is particularly true for the eastern coasts of the IP, as the presence of warm Mediterranean waters (especially at the end of the summer and the beginning of autumn) fosters such precipitation regimes (e.g., García-Herrera et al. 2005). We must bear in mind the results from Section 3, where it was evident that the significant increase in rainfall during blocking episodes over this region was not a result of an increase in the number of rainy days, thus suggesting a higher rate of heavy precipitation episodes during such atmospheric patterns. To check the efficiency of regional blocking patterns in promoting extreme rainfall events, we first computed the ratio between the frequency of blocking and strong zonal flow days with total precipitation above the local $90^{\text {th }}$ percentile for the ATL and EUR sectors, as presented in Figure 9.

Easternmost regions of Spain (for ATL and EUR blocks) and southernmost regions of Spain and Portugal (for ATL blocks) have higher ratios of extreme days during blocking episodes, when compared to strong zonal flows. The opposite result is found for northwestern IP, where the rainiest days are more associated with strong zonal flow patterns. Scrutinizing in further detail these different extreme precipitation regimes, we performed an extreme value analysis on the high-resolution precipitation dataset in order to: a) identify regions with homogeneous extreme precipitation regimes and find the model that better fits to 
their tailed distributions; b) analyze the contribution of different weather regimes to extreme daily precipitation episodes in these distinct sectors.

Several authors have shown that the Generalized Pareto (GP) Distribution provides adequate fits for oneside tailed distributions as the one found for precipitation extremes. The use of this type of fit for precipitation extremes is useful to model parameters such as probability maps of specific threshold exceedances, or return levels and periods. For example, Vicente-Serrano et al. (2009) used this fit to model extreme precipitation events in areas of Spain during different phases of the NAO and the Mediterranean Oscillation, and Toreti et al. (2010) characterized extreme winter precipitation in Mediterranean coastal sites in association with anomalous atmospheric circulation patterns.

When performing an extreme value analysis, we must bear in mind that the sample sizes of extreme episodes need to be large enough to provide satisfying fits. This is not the case for all considered gridpoints of the dataset, as in some areas heavy precipitation events are particularly rare. Furthermore, adjusting such a large number of local models requires some caution, taking into account that the associated errors resulting from each particular fit may eventually lead to unreliable results. Hence, the spatial comparison and coherence of such a large number of fits must be considered carefully. For this reason, we opted to first apply a spatial aggregation scheme, by considering four boxes of gridpoints. These boxes (Figure 10) have been defined taking into account the different responses in precipitation regimes found in the previous sections, as well as areas where extreme events are spatially coherent and often lead to abundant precipitation and have more severe impacts. In addition, a fifth test box was defined in central areas of the IP, to check the fit in a region with a different regime of precipitation extremes. In order to perform this spatial aggregation of the data, it is necessary to check if these subdomains defined heuristically actually represent homogeneous regions in terms of the extreme precipitation distribution. For this purpose, we used a methodology based on the L-Moments, where a statistic $\mathrm{H} 1$ checks the degree of heterogeneity of a region in terms of precipitation extremes (for further details on the methodology see Hosking and Wallis, 1997). This test was applied separately to each box by considering the gridpoint sub-series containing only rainy days with precipitation above the local $90^{\text {th }}$ percentile. For all boxes, the $\mathrm{H} 1$ statistic presented values lower than 1, i.e., below the required threshold to consider regions as homogeneous (Hosking and Wallis, 1997). Since the defined regions are homogenous, for each specific day we considered the absolute maximum of all gridpoints inside the box, in order to obtain the precipitation extreme daily series of each box. Such a process significantly increases the number of extreme precipitation records, as compared to that obtained by considering fits for individual gridpoints.

The above mentioned extreme daily series of each box were then used to assess whether the frequency of extreme precipitation events in each box and for different weather regimes is large enough to perform the extreme value analysis. Table 1 presents the number of rainy days with precipitation above the $90^{\text {th }}$ percentile, and the frequency of such extremes occurring under blocked and zonal days. This exercise also allows analyzing the effectiveness of each considered weather pattern on promoting extreme precipitation days in the different areas of the IP.

As it can be seen from Table 1, the sum of extreme days during blocked and zonal patterns corresponds to almost half of the total extreme days for any of the considered boxes. In the case of $\mathrm{BOX}_{\mathrm{NW}}$ and $\mathrm{BOX}_{\mathrm{N}}$, the contribution of blocking to extreme precipitation days is near $15 \%$, while that of strong zonal flows is around $30 \%$. In $\mathrm{BOX}_{\mathrm{SW}}$ and $\mathrm{BOX}_{\mathrm{E}}$, these results are reversed, in agreement with the overall pattern presented in Fig. 9, thus reinforcing the idea that blocking favors extreme events in these regions, while strong zonal flows (mainly those occurring over the ATL) are more decisive for extreme precipitation in the Atlantic areas of the IP. Regarding BOX $\mathrm{C}_{\mathrm{C}}$, there is a similar contribution of blocked and strong zonal flows, albeit with slightly higher percentages of extreme events during blocked patterns, particularly when they are located over the European sector. Therefore, the number of extreme precipitation events occurring under blocking and zonal flows is large enough to perform an extreme value analysis. 
We next explored the theoretical model that better captures the distribution of the extremes daily series of each box. This was done by applying different models to the daily series of each considered box and constructing L-Moment Ratio diagrams to visually check the convenience of each fit (Fig. 11). These diagrams clearly point to the GP fit as the most suitable one for our extreme precipitation series in all boxes. Besides this visual inspection, we later checked the goodness-of-fit of models for each sub-region using the Anderson-Darling test (Wilks, 2011), as it will be detailed further ahead.

In order to perform the GP fit (Beirlant, 2004) for extreme precipitation events in each box, we have followed a scheme similar to the one presented by Vicente-Serrano et al. (2009). Thus, we defined discrete blocking and zonal events as sequences of at least four days under those particular synoptic conditions. While blocked events are more frequent over Europe, zonal patterns are more frequent in the ATL sector. The results of this classification indicate that zonal events tend to last longer than blocked events ( $\sim 9$ and $\sim 7$ days, respectively), and that for both types of events ATL patterns persist for slightly longer periods than EUR patterns. Then, once again using the extreme daily series of the individual boxes (previously obtained from the daily maxima inside each of these sub-regions), we obtained two different new time-series for each box, each one having a single precipitation value associated to each specific weather event. These two series are comprised by: 1) the maximum daily value of each event ( $\left.\mathrm{P}_{\mathrm{MAX}}\right) ; 2$ ) the accumulated precipitation of each event $\left(\mathrm{P}_{\mathrm{TOT}}\right)$. This has been done in order to perform a temporal declustering over sequences of rainy days, and thus to avoid the presence of serial dependence or persistence.

Next, for each box, we followed a peak-over-threshold approach, by calculating the high percentiles of the series of rainy days, and then applying GP fits for the corresponding tails of the $\mathrm{P}_{\mathrm{TOT}}$ and $\mathrm{P}_{\text {MAX }}$ timeseries obtained for both weather patterns (blocked and strong events). In order to decide the more appropriate percentile threshold, we relied on both graphical (probability-probability plots, see Supplementary Material, S3 and S4) and formal (Anderson-Darling test) selection techniques. Taking this into account we finally opted for the $90^{\text {th }}$ percentile as a final threshold, and all presented GP fits were performed for the tail series based on this threshold. The confidence levels for the fits, as well as their corresponding tail and shape parameters are presented in Tables 2 and 3 .

Overall, the confidence levels obtained after performing the Anderson-Darling test are high (above 90\%), thus giving us confidence on most of the performed fits, and once again reinforcing on the convenience of the GP fit to model precipitation tail distributions. The location parameter of the fits illustrates very well the different contribution of distinct weather regimes to extreme daily precipitation episodes at the regional scale. Higher values of this parameter are found for blocked patterns in southern and eastern areas $\left(\mathrm{BOX}_{\mathrm{E}}\right.$ and $\left.\mathrm{BOX}_{\mathrm{SW}}\right)$, contrarily to northern regions $\left(\mathrm{BOX}_{\mathrm{N}}, \mathrm{BOX}_{\mathrm{NW}}\right.$ and $\left.\mathrm{BOX}_{\mathrm{C}}\right)$, where higher values are found for zonal flows. These regional differences become clearer when we analyze $\mathrm{P}_{\text {Tот, }}$, for which the changes on the location parameter from blocked to zonal flows are higher, particularly for BOX $_{\mathrm{NW}}$. This is not surprising, since: 1) extreme precipitation days in Mediterranean (Atlantic) areas of the IP are strongly linked to blocked patterns (strong zonal flows); 2) large sequences of moderate to heavy rainfall are frequent in northwest Iberia during strong zonal synoptic conditions; 3) torrential episodes in the Mediterranean coasts occur essentially at shorter time scales. We must recall that the mean duration of strong zonal flow events is slightly larger than that of blocking events. This is obviously important when comparing the probabilities for $\mathrm{P}_{\mathrm{TOT}}$, as different mean durations involve different expected accumulated values.

These results confirm the existence of different extreme precipitation regimes between northwestern and southeastern sectors of the IP, with the former being related to persistent moderate precipitating events and the latter by short-lived intense episodes. They also demonstrate that these regional differences are to a large extent due to different triggering large-scale weather regimes (strong zonal flows and blocking patterns, respectively). These distinct atmospheric configurations play a very different contribution to the occurrence of extreme events in those regions, and although they are both related to anomalies of the zonal flow, they exhibit nearly opposite synoptic features and very different persistence signatures, thus shaping regional differences in the tailed distributions of precipitating events. 


\section{Discussion}

In this work, we made a reassessment of blocking impacts in precipitation regimes over the Iberian Peninsula, taking advantage of the recently developed high-resolution datasets for the two Iberian (NCEP) and the high-resolution dataset (IBERIA02) clearly shows that only the latter can represent adequately specific regional impacts. Furthermore, the difference between the impacts caused by blocking episodes in different sectors (Atlantic and Europe) is also perfectly clear using the high-resolution data. Overall, blocking occurrence induces a negative to positive marked dipole in precipitation from northwest to southeast Iberia, with a northeast shift of the largest positive anomalies from ATL blocks to EUR blocks. We must recall that the blocking structures tend to migrate eastwards in most cases, and hence the regional precipitation responses partially reflect blocking impacts at different stages of the blocking lifecycle.

Increases in precipitation above 50\% are found in some regions during blocked synoptic patterns. In particular, positive precipitation anomalies extend to most of the IP domain during ATL blocks, being larger in southern and southeastern areas of the IP, while during EUR blocks they tend to be more restricted to eastern Mediterranean regions. Nevertheless, the relevance of blocking on precipitation vanishes as we move towards the northwest. In these regions, the blocked patterns only contribute to less than $10 \%$ of the total mean annual precipitation. Nearly opposite results are obtained for strong zonal flows. However, there are some important asymmetries in the precipitation signals between zonal and blocked patterns, suggesting some non-linear responses to changes in the westerly flow.

The synoptic configurations associated with blocking show negative Z500 anomalies to the south of the blocking centers. As a consequence, during blocking situations, storm-tracks tend to be deflected southwards, towards the IP domain, explaining part of the precipitation excess found over Iberia. Still, this shift is not completely compatible with the blocking-related precipitation deficits in northwest Iberia. In this case, changes in transport and moisture availability during blocking days (involving a reduced efficiency of Atlantic frontal systems located northwards of the IP) explain the reduction in rainfall amount. Other important dynamical factors seem to play a role in the precipitation responses to blocking over the Mediterranean region. In particular, the simultaneous increases in low pressure systems (particularly cut-off lows) affecting the area and atmospheric instability help to understand the blocking signatures in precipitation over the Mediterranean coast. This important rise in the frequency of cut-off lows in the IP area (particularly during ATL blocks) is in agreement with Nieto et al. (2007), which noticed the increase of COL activity in the southern flank of Euro-Atlantic blocking systems. This sustains the importance of dynamical factors in shaping the precipitation regimes of the IP, especially in the Mediterranean areas. Furthermore, the high-resolution dataset reveals substantial differences on the precipitation responses to blocking over relatively small regions (mainly in the Mediterranean). This indicates a major importance of local processes (such as moisture convergence and deep convection) on the precipitation regimes of that part of Iberia and calls for further investigation, including the relevance and impact of Sea Surface Temperatures, and their connections and feedbacks with the particular synoptic patterns that arise from blocking situations.

On the other hand, we have found that, for most of the IP, the precipitation increases associated with blocking are due to changes in precipitation amount rather than changes in the number of precipitation days. In fact, despite the overall increase in precipitation under blocking action, there is either a concurrent decrease in the number of measurable rainfall days in most of the regions of Iberia (more pronounced in NW Iberia) or irrelevant changes in the number of rainy days. This fact indicates that rainfall regimes during blocking days are more extreme in southeastern Iberia, where the blocking 
contribution to annual totals is the greatest. The results are supported by the existence of a northwestsoutheast dipole in the frequency rate of days with extreme precipitation occurring under strong zonal flow and blocking.

Finally, we have performed an Extreme Value Analysis, fitting Generalized Pareto distributions to maximum daily precipitation and total accumulated precipitation series for distinct homogeneous subregions inside the IP during blocking and strong zonal episodes. This approach shows that extreme precipitation events during blocking conditions tend to be short-lived (i.e., isolated extremes at the daily scale), mainly in the Mediterranean, while zonal events are more relevant concerning the total episode accumulated precipitation in northwest Iberia.

\section{Acknowledgments}

Pedro M. Sousa was supported by the Portuguese Science Foundation (FCT) through a doctoral grant (SFRH/BD/84395/2012).

Alexandre M. Ramos was also supported by FCT in a postdoctoral grant (FCT/DFRH/SFRH/BPD/84328/2012).

This work was partially supported by FEDER funds through the COMPETE (Programa Operacional Factores de Competitividade) Programme and by national funds through FCT (Fundação para a Ciência e a Tecnologia, Portugal) through project STORMEx FCOMP-01-0124-FEDER-019524 (PTDC/AACCLI/121339/2010).

\section{References}

Barriopedro D, García-Herrera R, Lupo AR, Hernández E (2006) A climatology of Northern Hemisphere blocking. J Clim 19: 1042-1063. doi: 10.1175/JCLI3678.1

Barriopedro D, García-Herrera R, Trigo RM (2010) Application of blocking diagnosis methods to General Circulation Models. Part I: A novel detection scheme. Climate Dynamics 35: 1373-1391. doi: $10.1007 / \mathrm{s} 00382-010-0767-5$

Barriopedro D, Fischer EM, Luterbacher J, Trigo RM, García-Herrera R (2011) The hot summer of 2010: redrawing the temperature record map of Europe. Science 332: 220-224. doi: 10.1126/science.1201224

Beirlant J, Goegebeur Y, Teugels J, Segers, J (2004) Statistics of Extremes: Theory and Applications. Wiley, USA.

Belo-Pereira M, Dutra E, Viterbo P (2011) Evaluation of global precipitation data sets over the Iberian Peninsula. J. Geophys. Res. 116: D20101. doi:10.1029/2010JD015481

Buehler T, Raible CC, Stocker TF (2011) The relationship of winter season North Atlantic blocking frequencies to extreme cold or dry spells in the ERA-40. Tellus Ser. A 63: 212-222. doi:10.1111/j.16000870.2010.00492.x

Croci-Maspoli M, Schwierz C, Davies HC (2007) Atmospheric blocking: space-time links to the NAO and PNA. Clim Dyn 29: 713-725. doi: 10.1007/s00382-007-0259-4

Davini P, Cagnazzo C, Neale R, Tribbia J (2012) Coupling between Greenland blocking and the North Atlantic Oscillation pattern. Geophys. Res. Lett. 39: L14701. doi:10.1029/2012GL052315.

Fragoso M, Trigo RM, Zêzere JL, Valente MA (2010) The exceptional rainfall episode registered in Lisbon on 18 February 2008. Weather 65(2): 31-35. doi:10.1002/wea.513 
Garcia-Herrera R, Paredes D, Trigo RM, Trigo IF, Hernández H, Barriopedro D, Mendes MT (2007) The outstanding 2004-2005 drought in the Iberian Peninsula: associated atmospheric circulation. J. Hydrometeorol. 8: 483-498, 2007. doi: http://dx.doi.org/10.1175/JHM578.1

Herrera S, Gutierrez JM, Ancell R, Pons MR, Frias MD, Fernandez J (2012) Development and Analysis of a 50 year high-resolution daily gridded precipitation dataset over Spain (Spain02). International Journal of Climatology 32: 74-85. doi: 10.1002/joc.2256

Homar V, Romero R, Ramis C, Alonso S (2002) Numerical study of the October 2000 torrential precipitation event over eastern Spain: analysis of the synoptic-scale stationarity. Annales Geophysicae 20 (12): 2047-2066.

Hosking JRM, Wallis JR (1997) Regional Frequency Analysis, An Approach Based on L-Moments. Cambridge University Press, Cambridge, UK.

Kalnay E, Kanamitsu M, Kistler R, Collins W, Deaven D, Gandin L, Iredell M, Saha S, White G, Woollen J, Zhu Y, Chelliah M, Ebisuzaki W, Higgins W, Janowiak J, Mo KC, Ropelewski C, Wang J, Leetmaa A, Reynolds R, Jenne R, Joseph D (1996) The NCEP/NCAR 40-Year Reanalysis Project. Bull. Am.788 Meteorol. Soc. 77 (3): 437-471. doi: 10.1175/1520-0477(1996)077<0437:TNYRP>2.0.CO;2

Masato G, Hoskins BJ, Woollings TJ (2012) Wave-breaking characteristics of mid-latitude blocking. Quarterly Journal of the Royal Meteorological Society 138: 1285-1296. doi: 10.1002/qj.990

Nieto R, Gimeno L, de la Torre L, Ribera P, Gallego D, García-Herrera R, García JA, Núñez M, Redaño A, Lorente J (2005) Climatological features of Cut-off low systems in the Northern Hemisphere. Journal of Climate, 18: 3085-3113. doi: http://dx.doi.org/10.1175/JCLI3386.1

Nieto R, Gimeno L, de la Torre L, Ribera P, Barriopedro D, García-Herrera R (2007) Interannual variability of cut-off low systems over the European sector: the role of blocking and the northern hemisphere circulation modes. Meteorology and Atmospheric Physics 96: 85-101. doi: http://dx.doi.org/10.1007/s00703-006-0222-7

Quiroz RS (1984) The climate of 1983-84 winter. A season of strong blocking and severe cold in North America. Mon Weather Rev 112: 1894-1912. doi: DOI: 10.1175/15200493(1984)112<1894:TCOTWS>2.0.CO;2

Pfahl S (2014) Characterising the relationship between weather extremes in Europe and synoptic circulation features. Nat. Hazards Earth Syst. Sci. 14: 1461-1475. doi:10.5194/nhess-14-1461-2014

Ramos AM, Trigo RM, Liberato MLR. (2014) A ranking of high-resolution daily precipitation extreme events for the Iberian Peninsula. Atmosph. Sci. Lett. 15: 328-334. doi: 10.1002/asl2.507

Ramos AM, Trigo RM, Liberato MLR, Tome R (2015) Daily precipitation extreme events in the Iberian Peninsula and its association with Atmospheric Rivers. Journal of Hydrometeorology (in press). doi: 10.1175/JHM-D-14-0103.1

Rex DF (1950a) Blocking action in the middle troposphere and its effect upon regional climate. Part I: An aerological study of blocking action. Tellus 2: 196-211.

Rex DF (1950b) Blocking action in the middle troposphere and its effect upon regional climate. Part II: The climatology of blocking action. Tellus 2: 275-301.

Rex DF (1951) The effect of Atlantic blocking action upon European climate. Tellus 3: 1-16.

Ruti PM, Dell'Aquila A, Giorgi F (2014) Understanding and attributing the Euro-Russian summer blocking signatures. Atmospheric Science Letters 15(3): 204-210. doi: 10.1002/as12.490 
641 Santos JA, Andrade C, Corte-Real J (2008) North Atlantic transient eddies and winter precipitation in 642 Portugal. Geophysical Research Abstracts 10: EGU2008-A-01820.

643 Santos JA, Pinto JG, Ulbrich U (2009) On the development of strong ridge episodes over the eastern 644 North Atlantic. Geophysical Research Letters 36: L17804. doi:10.1029/2009GL039086

645 Scherrer SC, Croci-Maspoli M, Schwierz C, Appenzeller C (2006) Two-dimensional indices of 646 atmospheric blocking and their statistical relationship with winter climate patterns in the Euro-Atlantic 647 region, Int. J. Climatol. 26, 233-249. doi: 10.1002/joc.1250

648 Sillmann J, Croci-Maspoli M (2009) Present and future atmospheric blocking and its impact on European 649 mean and extreme climate. Geophysical Research Letters 36: L10702, doi:10.1029/2009GL038259

650 Treidl RA, Birch EC, Sajecki P (1981) Blocking action in the Northern Hemisphere: A climatological 651 study. Atmos.-Ocean 19: 1-23. doi: 10.1080/07055900.1981.9649096

652 Toreti A, Xoplaki E, Maraun D, Kuglitsch FG, Wanner H, Luterbacher J (2010) Characterisation of 653 extreme winter precipitation in Mediterranean coastal sites and associated anomalous atmospheric 654 circulation patterns. Nat. Hazards Earth Syst. Sci. 10: 1037-1050. doi:10.5194/nhess-10-1037-2010

655 Trigo, I. F., 2006: Climatology and interannual variability of stormtracks in the Euro-Atlantic sector: a 656 comparison between ERA-40 and NCEP/NCAR reanalyses. Clim. Dyn., 26, 127-143. DOI $657 \quad 10.1007 / \mathrm{s} 00382-005-0065-9$

658 Trigo RM, Trigo IF, DaCamara CC, Osborn TJ (2004) Winter blocking episodes in the European-Atlantic 659 sector: climate impacts and associated physical mechanisms in the reanalysis. Clim Dyn 23: 17-28. doi: $660 \quad 10.1007 / \mathrm{s} 00382-004-0410-4$

661 Trigo RM, Añel J, Barriopedro D, García-Herrera R, Gimeno L, Nieto R, Castillo R, Allen MR, Massey 662 N (2013) The record Winter drought of 2011-12 in the Iberian Peninsula. In: Peterson TC, Hoerling MP, 663 Stott PA, Herring S (eds) Explaining Extreme Events of 2012 from a Climate Perspective. Bulletin of the 664 American Meteorological Society 94 (9): S41-S45.

665 Vicente-Serrano SM, Beguería S, Lopez-Moreno JI, El Kenawy AM, Angulo-Martinez M (2009) Daily 666 atmospheric circulation events and extreme precipitation risk in northeast Spain: Role of the North 667 Atlantic Oscillation, the Western Mediterranean Oscillation, and the Mediterranean . J. Geophys. Res. 668 114: D08106. doi:10.1029/2008JD011492

669 Wilks DS (2011) Statistical Methods in the Atmospheric Sciences (vol. 100). Academic Press, USA.

670 Woollings T, Charlton-Perez A, Ineson S, Marshall AG, Masato G (2010) Associations between 671 stratospheric variability and tropospheric blocking. J. Geophys. Res. 115: D06108. 672 doi:10.1029/2009JD012742 
Fig. 1 - Top: Boxes identifying the considered sectors for blocking center location: ATL - from 30W to OW; EUR - from OE to 30E. The shadings indicate the annual mean frequency of blocking center locations in each gridpoint. Blocks outside the $45 \mathrm{~N}$ to $70 \mathrm{~N}$ latitude strip were discarded in both sectors. Bottom: Seasonal frequencies of blocking center location in each sector during 1950-2007 (in percentage relative to the total number of days in the season).

Fig. 2 - Composites of the daily anomalies (shaded areas) and absolute values (isolines) of $500 \mathrm{hPa}$ geopotential height for blocking centers in each sector and for all seasons. All values are in decameters (dam) and the thick line represents the 550 dam isohypse.

Fig. 3 - Seasonal composites of daily precipitation anomalies (\%) in the Iberian Peninsula for blocking center days in each considered sector using (and comparing) the low resolution NCEP/NCAR dataset with the high resolution IBERIA02 dataset. Regions where the anomalies are statistically significant at the 5\% level are represented with dots. Anomalies for gridpoints with total seasonal precipitation below $50 \mathrm{~mm}$ were not considered (grey crosses).

Fig. 4 - Annual composites of daily precipitation anomalies (\%) in the Iberian Peninsula for blocking (left column) and strong zonal flow (center column) days in the Atlantic (upper row) and European (lower row) sectors. The difference between the regional blocking and strong zonal flow composites is presented in the right panels. Only statistically significant anomalies at the 5\% level are shown.

Fig. 5 - Increase (blue shades) or decrease (red shades) in the number of days with total precipitation above $1 \mathrm{~mm}$ during blocked patterns (upper panel) and strong zonal flows (lower panel), when compared with the complete 1950-2007 climatology (in percentage). Solid black lines represent the contribution (in percentage) of the corresponding synoptic pattern to the annual total precipitation.

Fig. 6 - Annual composites of the daily Integrated Vapour Transport (IVT, in $\mathrm{kg} \mathrm{m}^{-1} \mathrm{~s}^{-1}$, blue shading), the Lifted Index anomaly (LI, in ${ }^{\circ} \mathrm{C}$, reddish thick lines), 500hPa geopotential height (Z500, in dam, thin black lines - the thicker black line corresponds to the 550 dam isohypse) and mean horizontal transport (black arrows, $\mathrm{kg} \mathrm{m}^{-1}, \mathrm{~s}^{-1}$ ) for blocking (left panels) days, zonal (middle panel) days and their difference (right panel). Upper (lower) row panels correspond to the Atlantic (European) sector composites.

Fig. 7 - Top: Annual mean frequency of non-stationary cyclone centers in the Atlantic-European sector (counted in $2.5^{\circ} \times 2.5^{\circ}$ boxes). Bottom: annual mean changes (in \%) in the cyclone frequency during blocking episodes in the Atlantic (bottom left) and European (bottom right) sectors; increases are shown with blue shading (solid white lines) and decreases with red shading (dotted white lines). Anomalies are only depicted in boxes where at least one cyclone per year was registered during the 1950-2007 climatology.

Fig. 8 - Top: Annual mean frequency of cut off lows in the European-Mediterranean sector (counted in $2.5^{\circ} \times 2.5^{\circ}$ boxes). Bottom: annual mean change (in \%) in the frequency of cut-off lows during blocking episodes in the Atlantic (bottom left) and European (bottom right) sectors. Areas of increase (decrease) are shown in blue (red). Anomalies are only depicted in boxes where at least one cut-off per year was registered during the 1950-2007 climatology. Black dots represent the areas with significant decreases that do not achieve that threshold.

Fig. 9 - Extreme precipitation efficiency: quotient between the number of blocking days with daily precipitation above the $90^{\text {th }}$ percentile and the number of zonal days with daily precipitation above the $90^{\text {th }}$ percentile (in \%) in the ATL (left panel) and EUR (right panel) sectors. Quotients above the $100 \%$ isoline (thick black lines) are represented by darker reddish shading.

Fig. 10 - Boxes defined for the Generalized Pareto fit: northwest $\left(\mathrm{BOX}_{\mathrm{NW}}\right)$; north $\left(\mathrm{BOX}_{\mathrm{N}}\right)$, southwest $\left(\mathrm{BOX}_{\mathrm{SW}}\right)$; east $\left(\mathrm{BOX}_{\mathrm{E}}\right)$ and central $\left(\mathrm{BOX}_{\mathrm{C}}\right)$. These boxes were defined taking into account the precipitation anomaly patterns found in section 3 , and also the Iberian Peninsula geography and socioeconomic factors. 
Fig. 11 - L-Moment Ratio diagrams for series of precipitation days above the 90th percentile in the five considered boxes inside the Iberian Peninsula. Different curves represent different types of Extreme Value distributions and grey dots represent correspond to the observed values in each box.

724

Table 1 - Number of extreme rainy days (above $1 \mathrm{~mm}$, with total precipitation above the $90^{\text {th }}$ percentile) for each box, and the relative contribution of each considered weather pattern (in percentage with respect to the total number of extreme rainy days).

Table 2 - Confidence levels (bold) after the Anderson-Darling test, the tail parameter, and the scale parameter of each GP fit applied to the tailed distribution (above the $90^{\text {th }}$ percentile) of the $\mathrm{P}_{\mathrm{MAX}}$ series of the five considered boxes of gridpoints, during blocking (left columns) and strong zonal events (right columns) in the ATL and EUR sectors.

733 Table 3 - Same as Table 2, but for the $\mathrm{P}_{\text {TOT }}$ time-series 


\section{Blocking center locations}

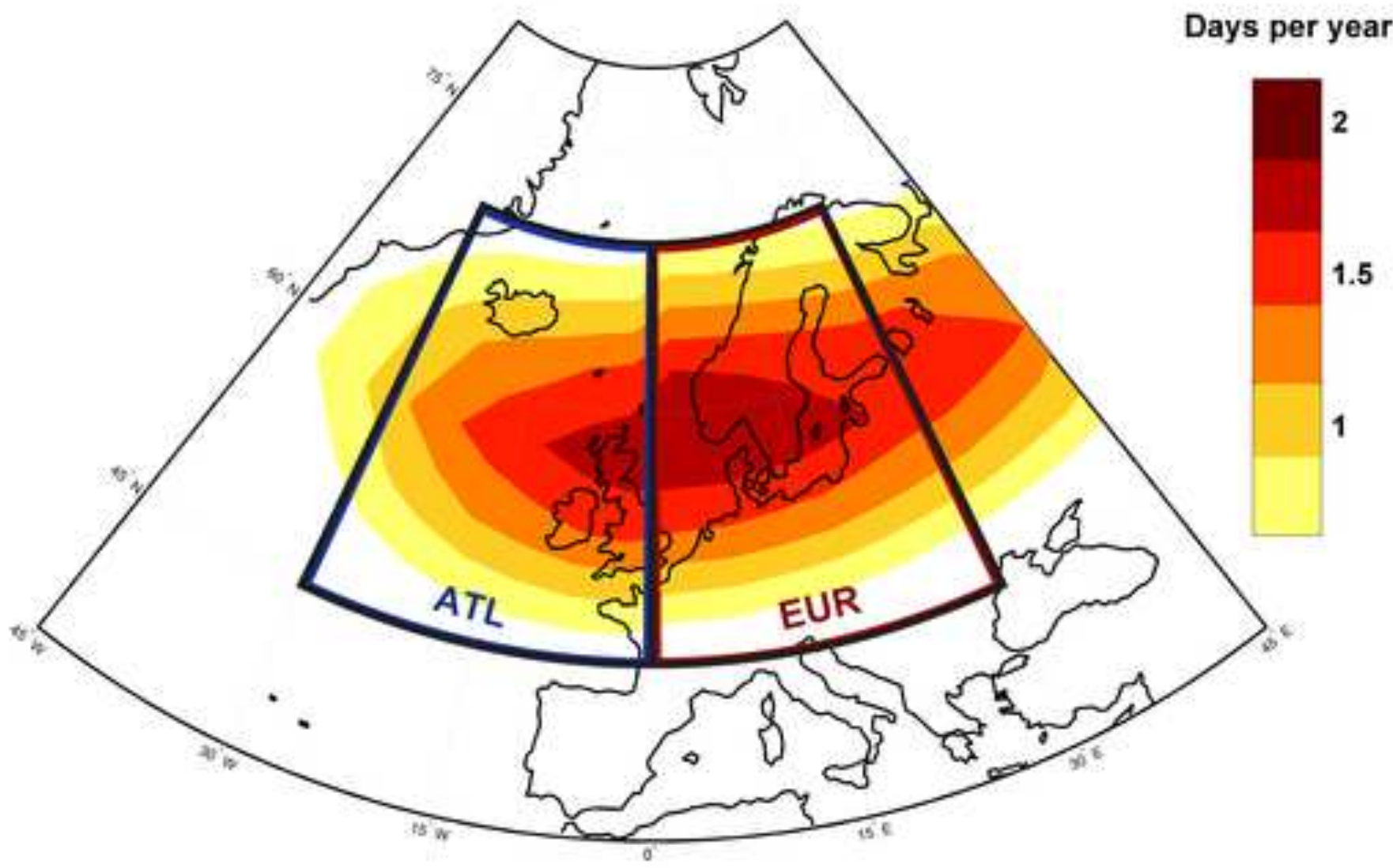

Blocking frequency by sector and by season

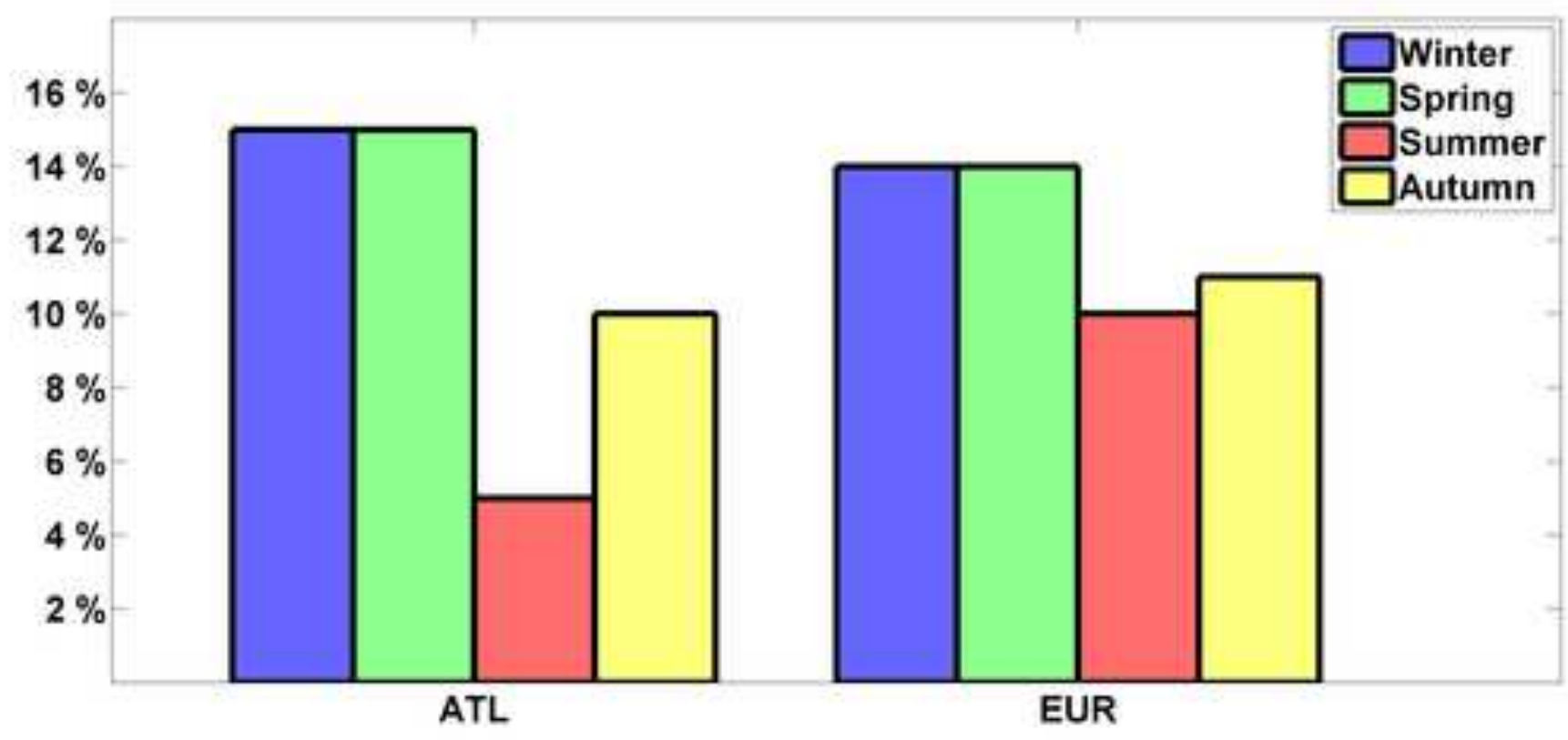


Figure
Click here to download Figure: Fig_2.tif
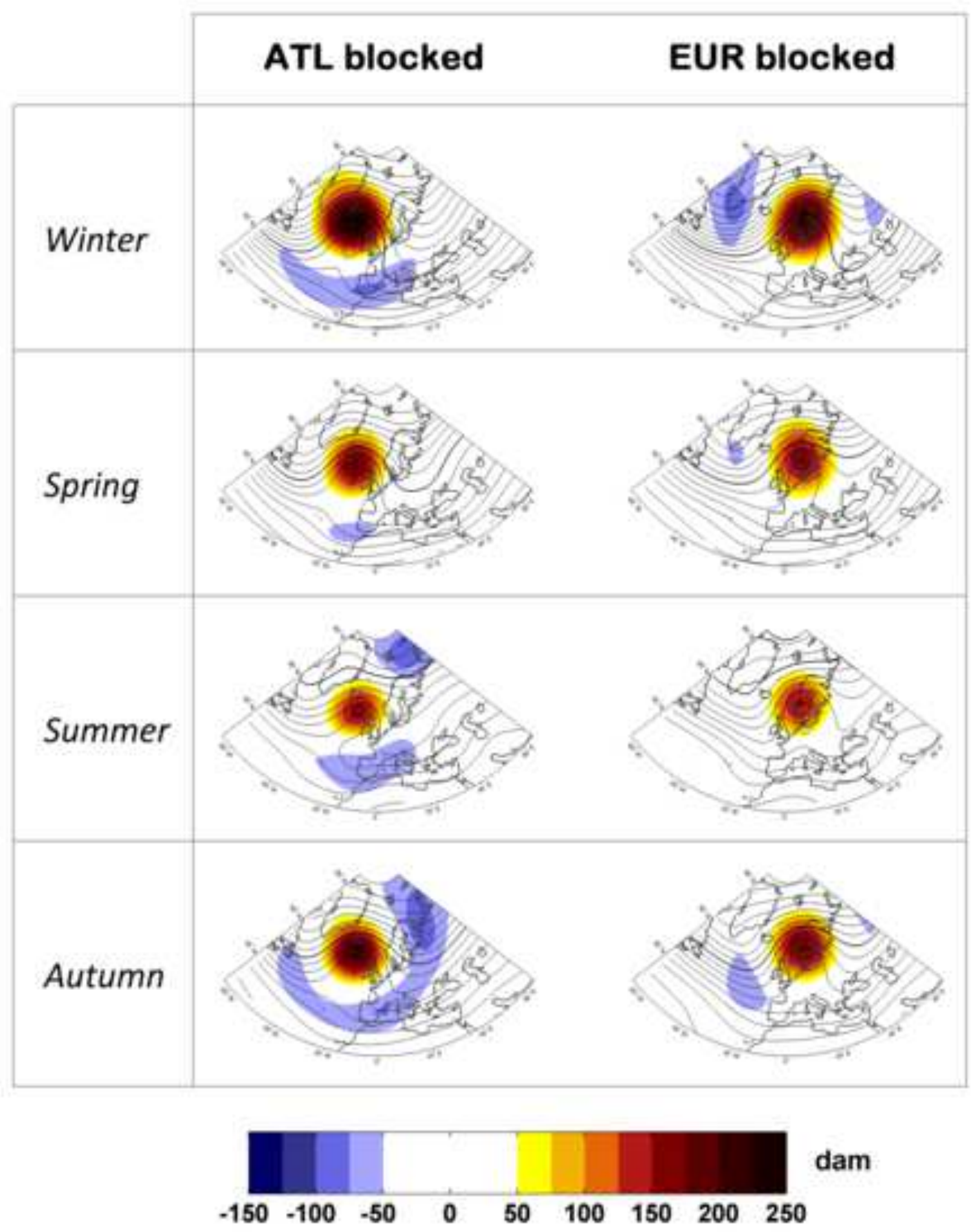


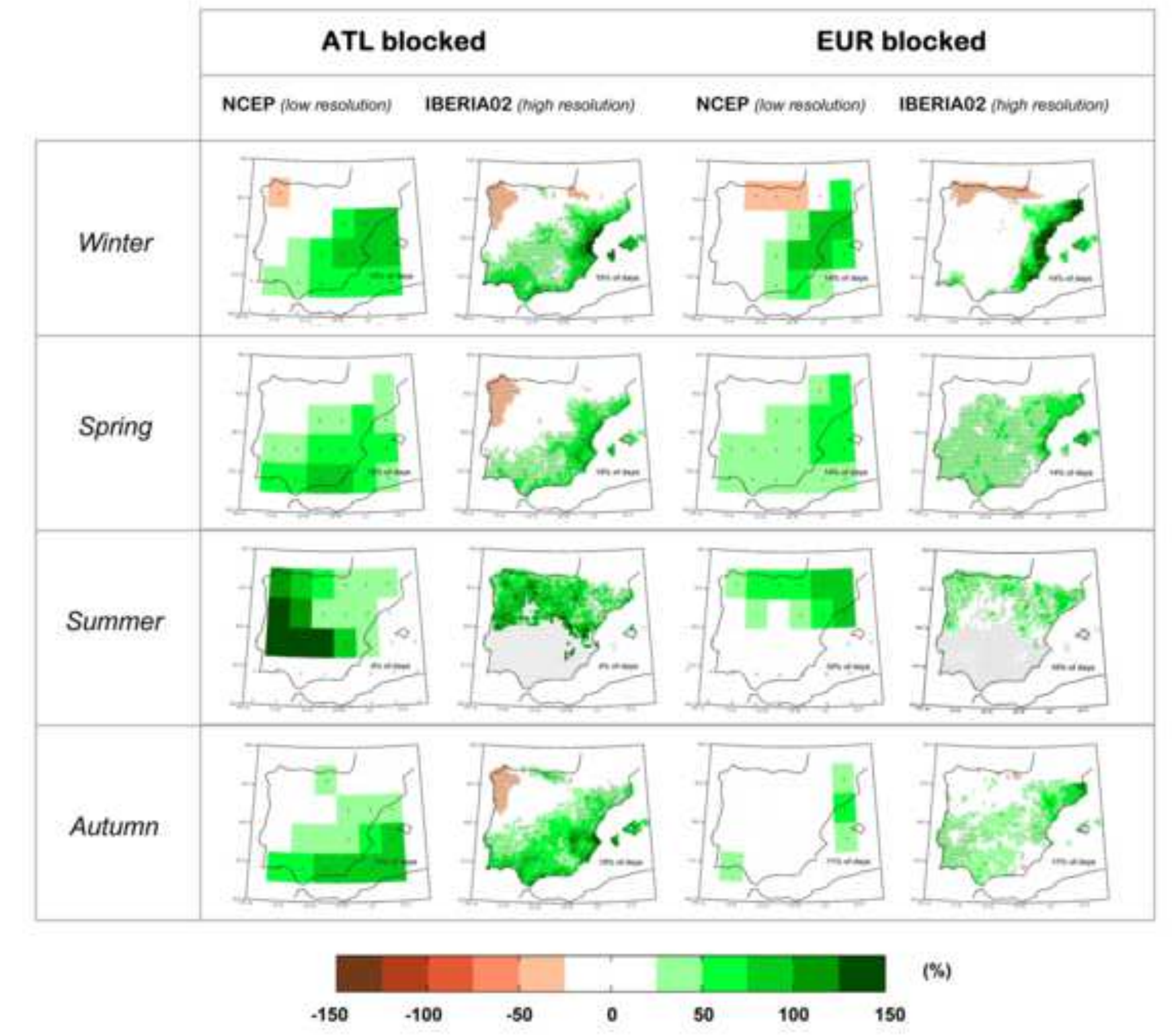



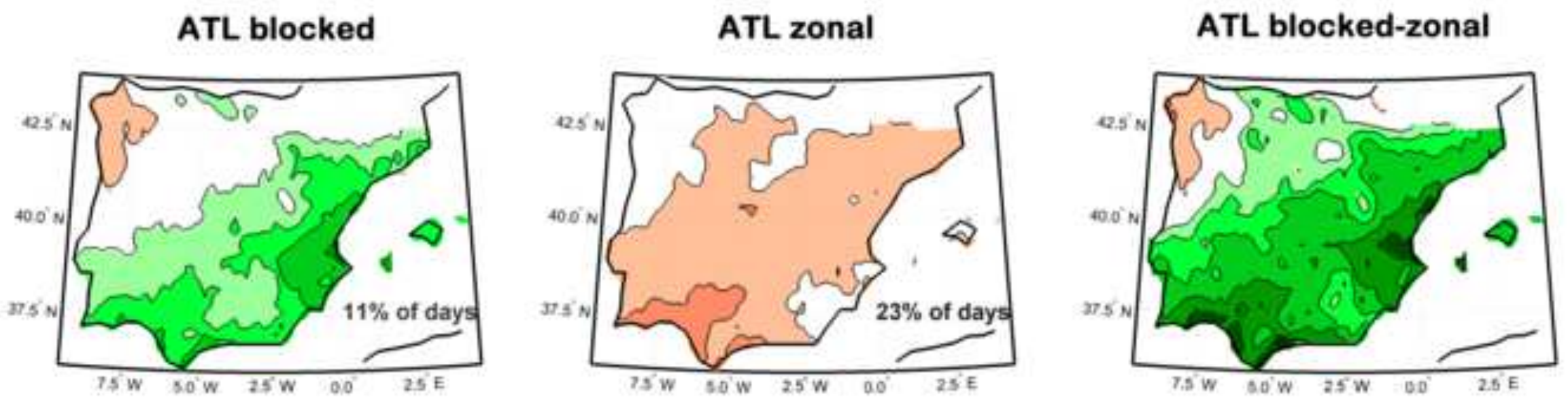

\section{EUR blocked}

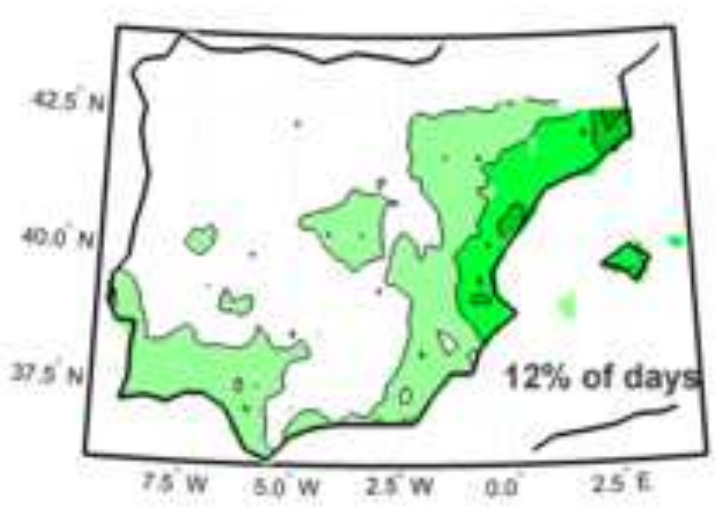

\section{EUR zonal}

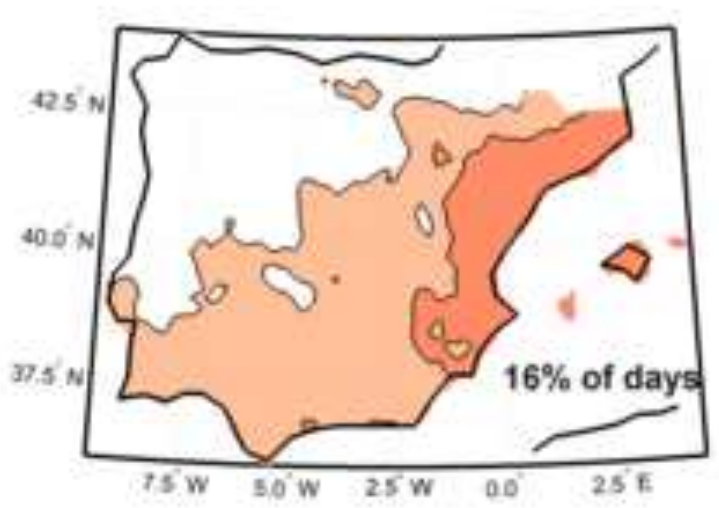

\section{EUR blocked-zonal}

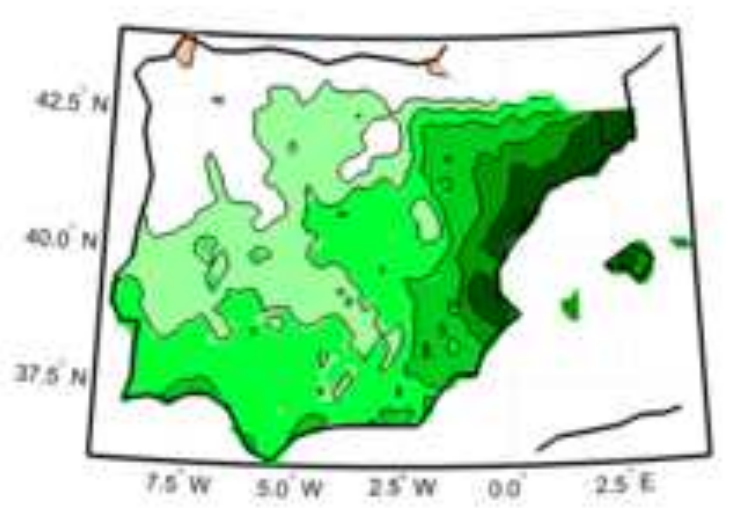

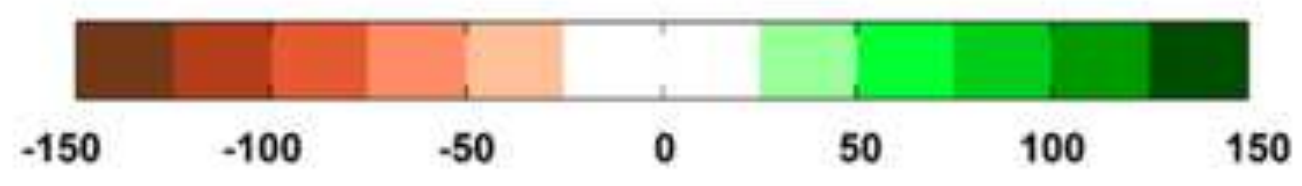

(\%) 
ATL blocked

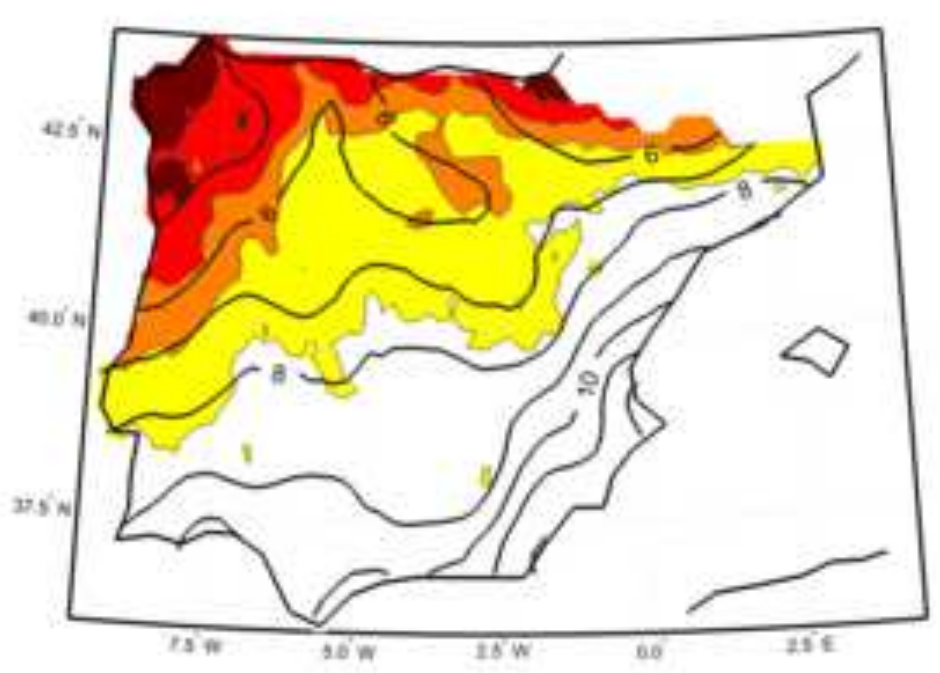

ATL zonal

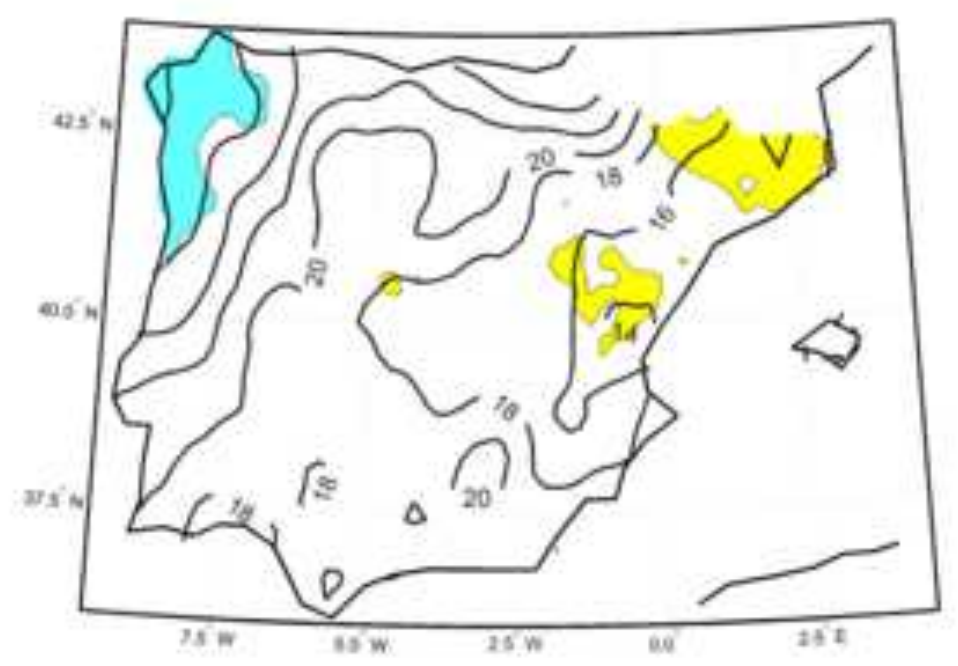

EUR blocked

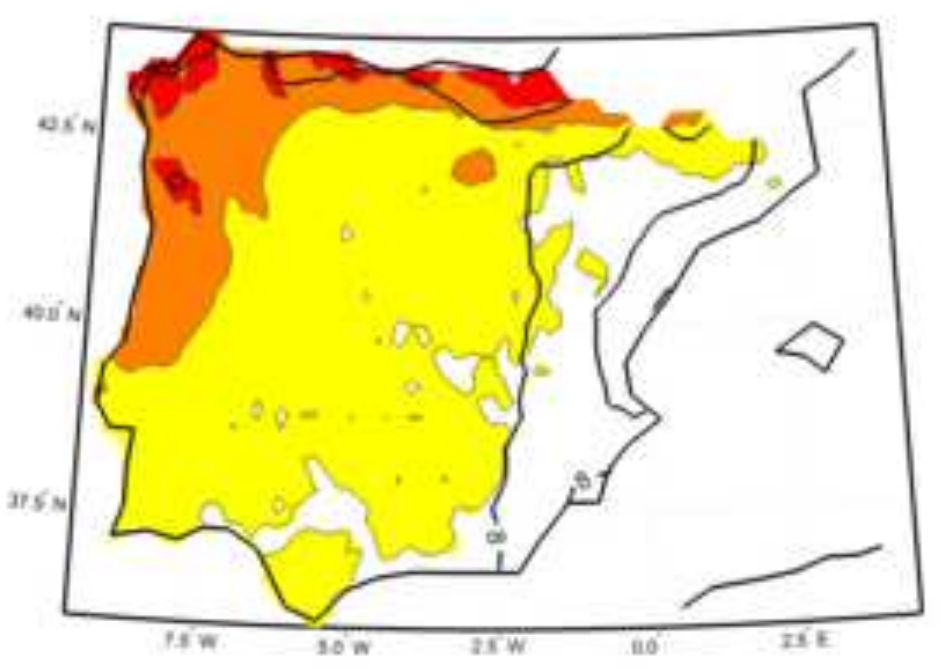

EUR zonal

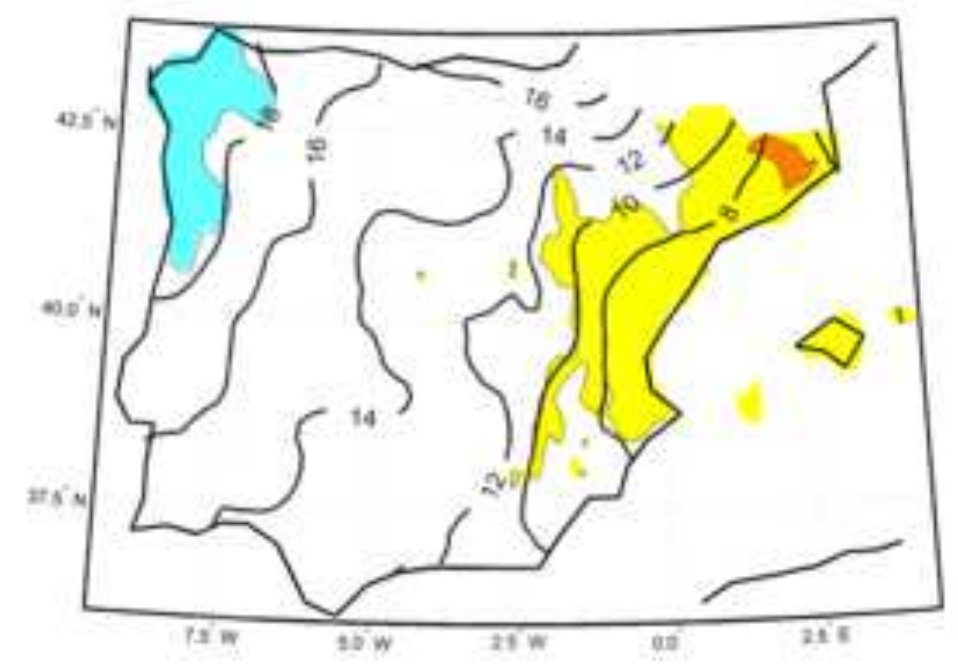

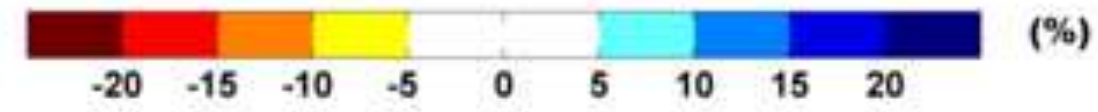


ATL blocked

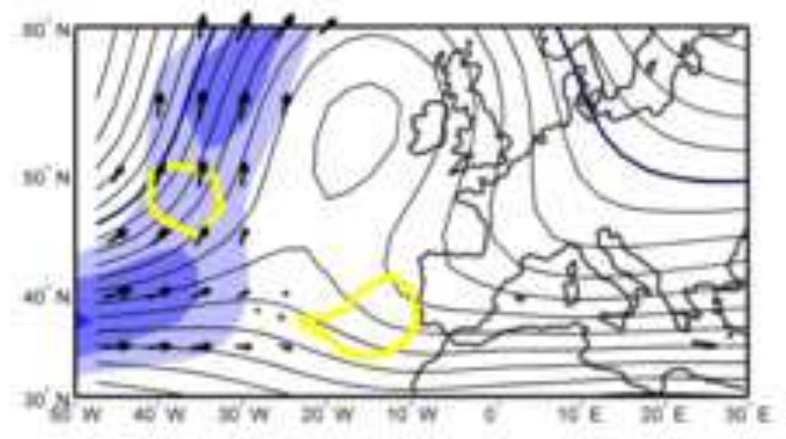

EUR blocked

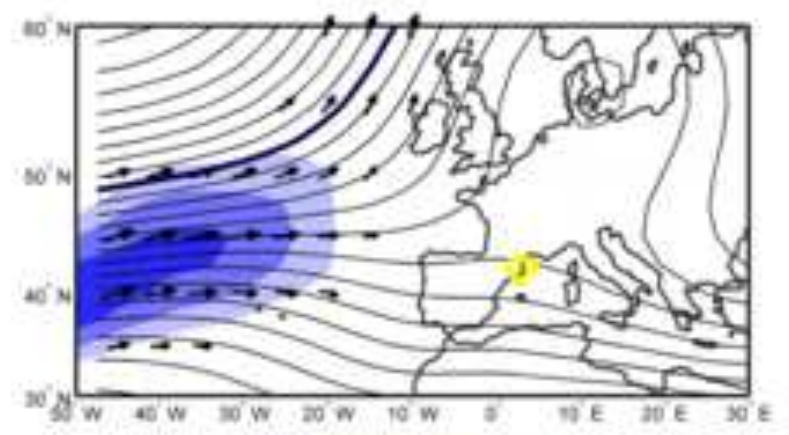

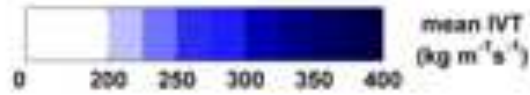

ATL zona!

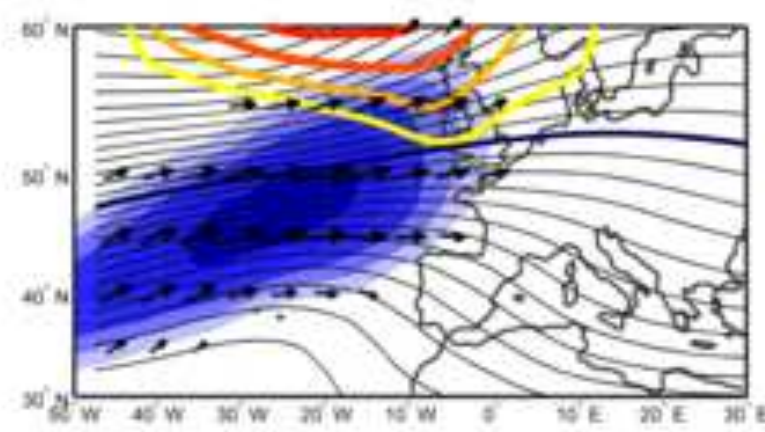

EUR zonal

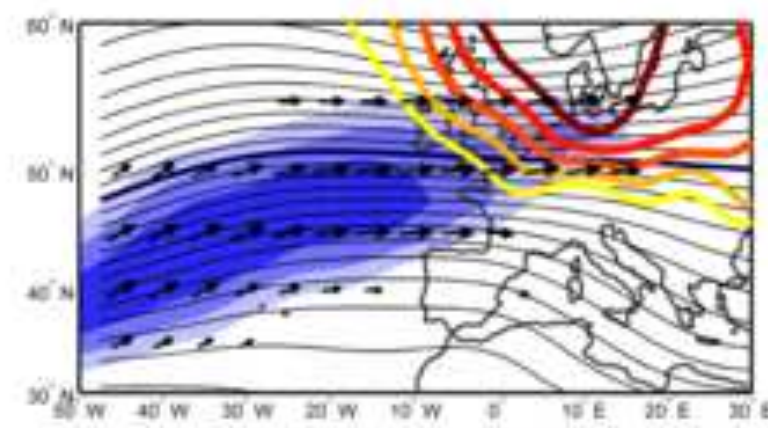

Ut anomaly

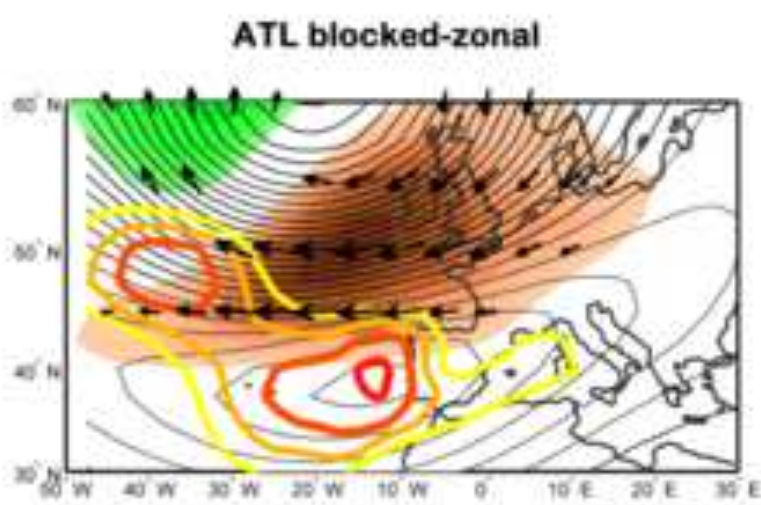

EUR blocked-zonal
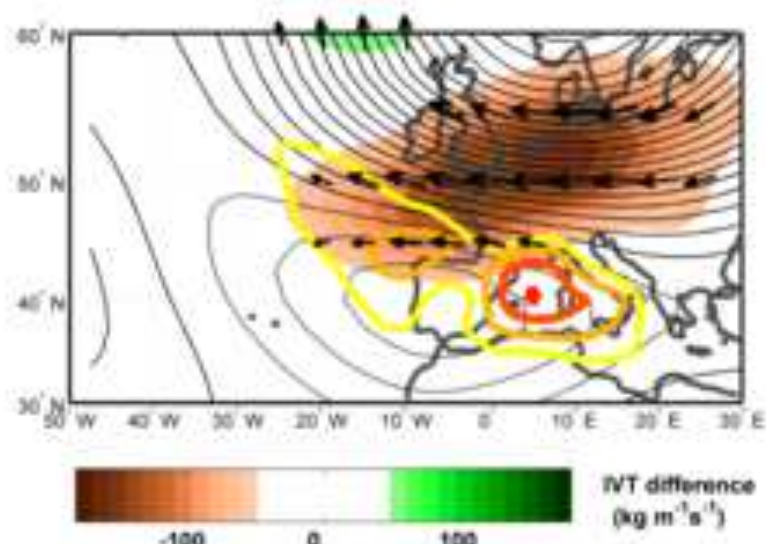

190

109

3

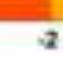

$+1$ 

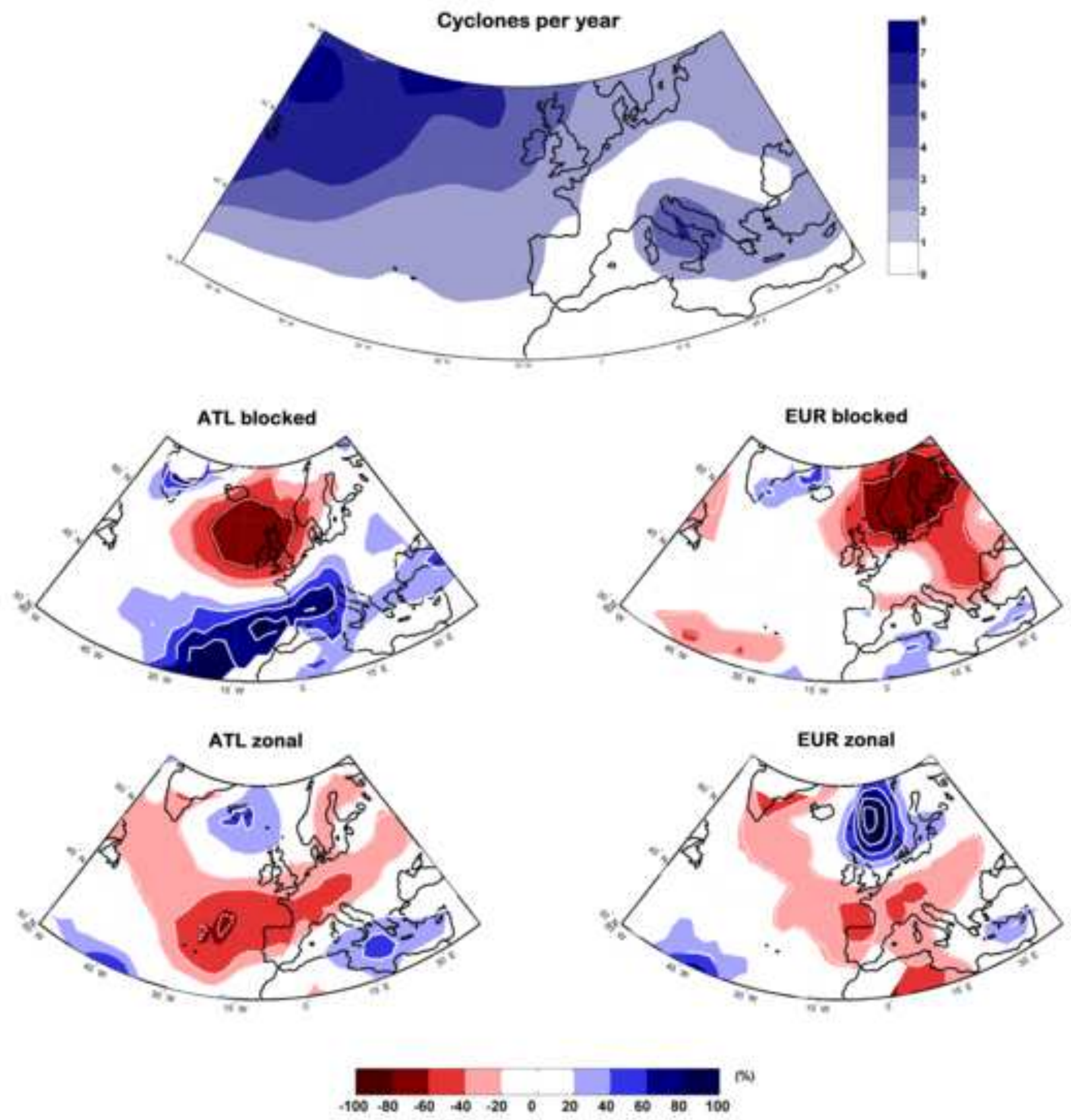

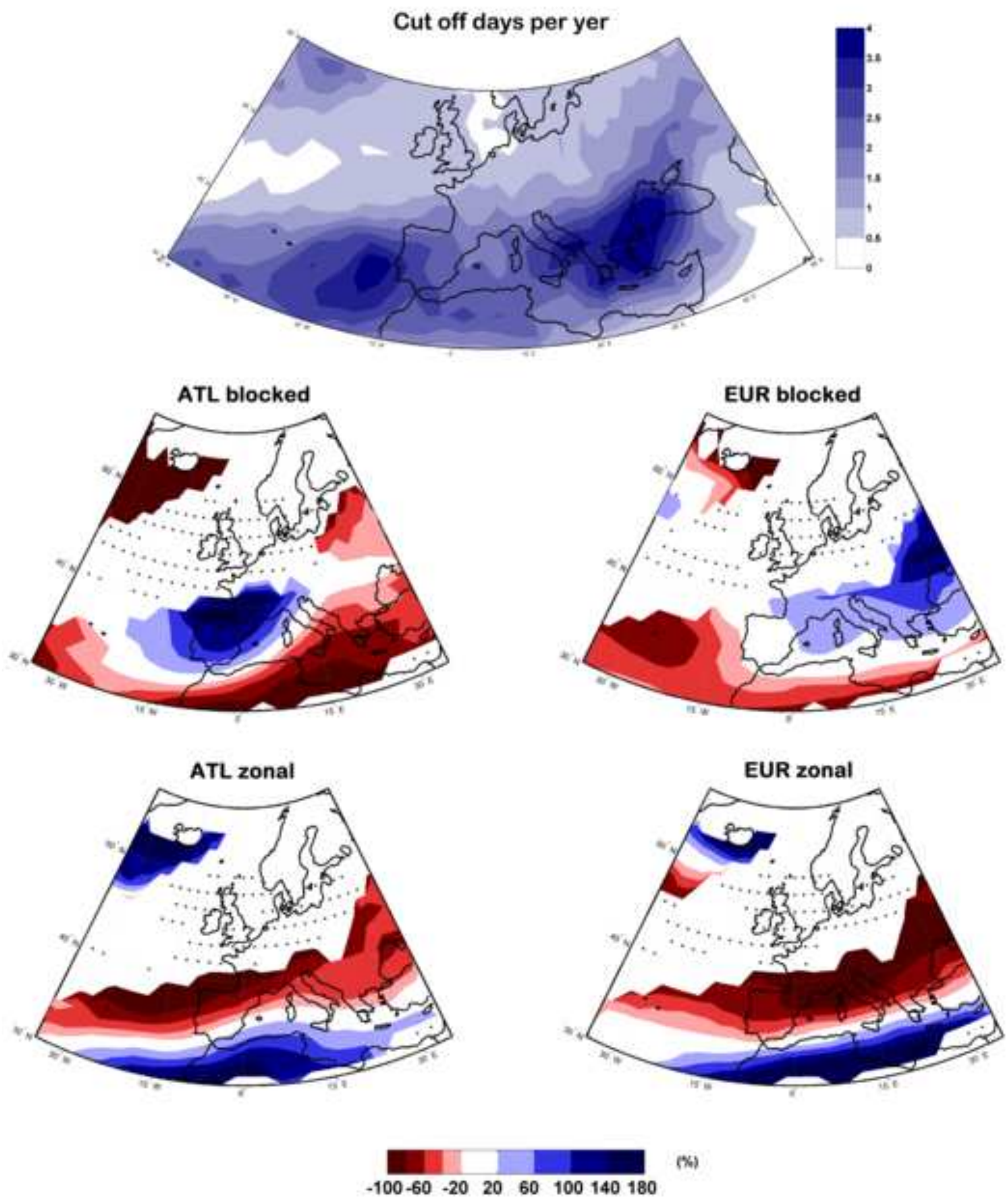

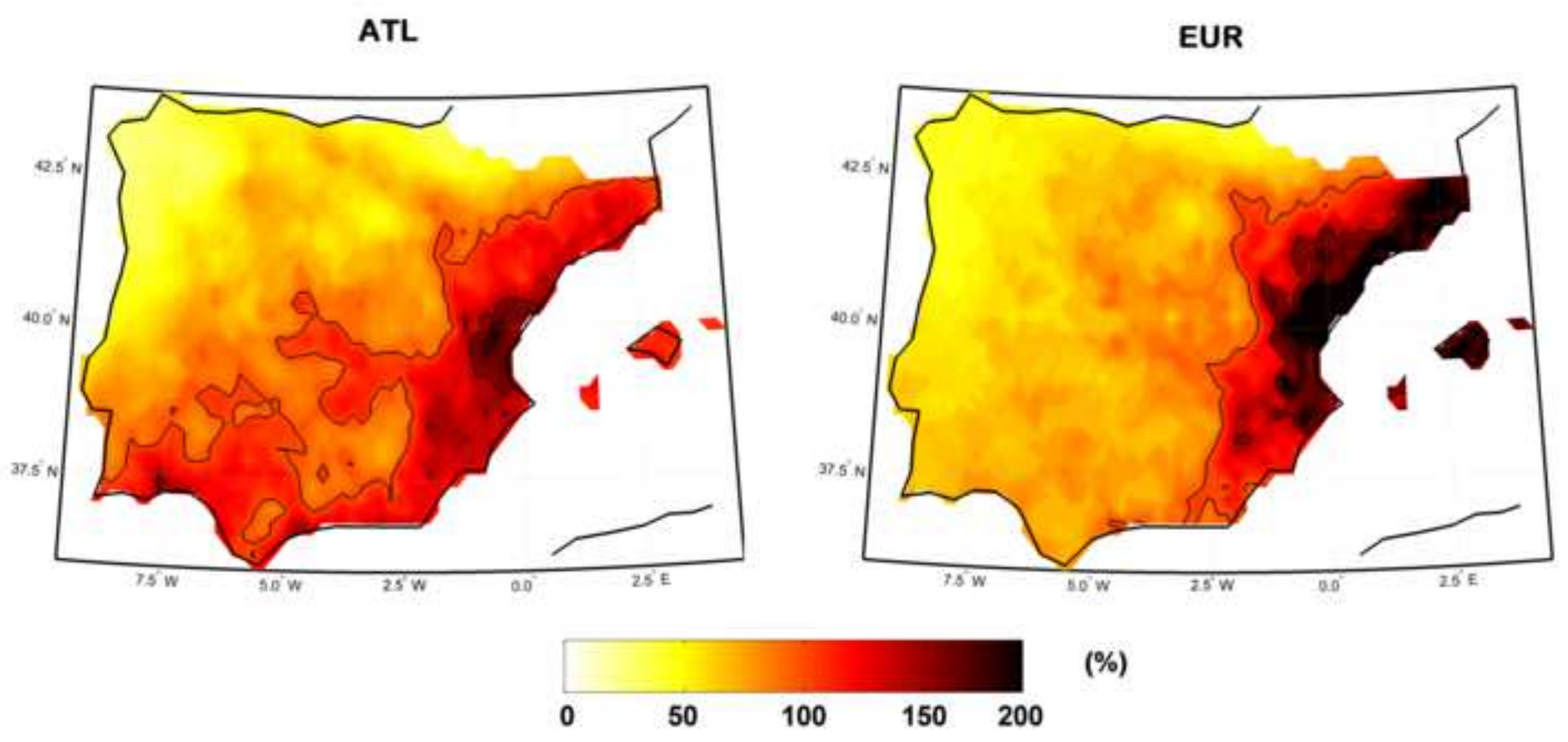

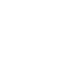




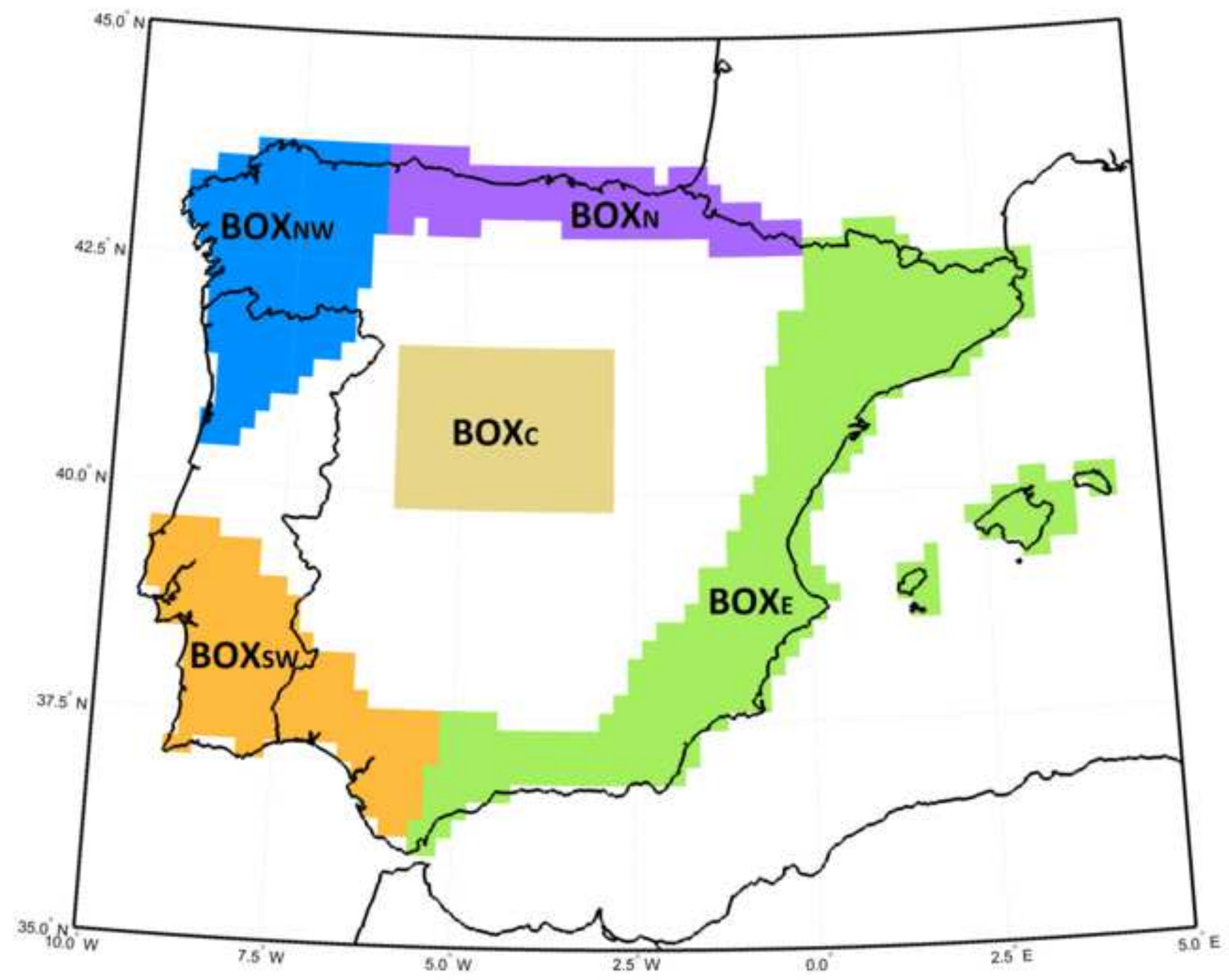



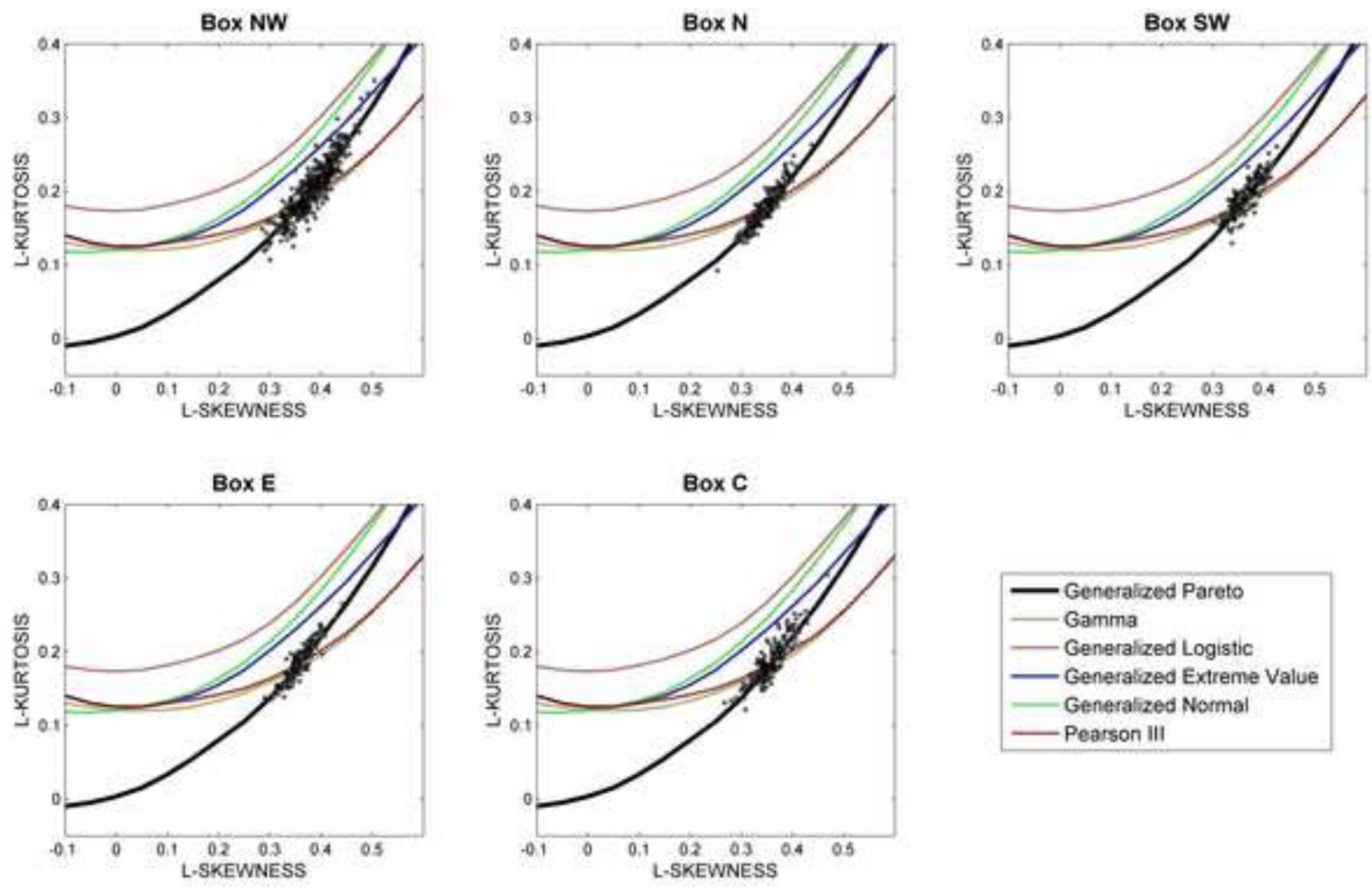
Table 1 - Number of extreme rainy days (above $1 \mathrm{~mm}$, with total precipitation above the $90^{\text {th }}$ percentile) for each box, and the relative contribution of each considered weather pattern (in percentage with respect to the total number of extreme rainy days).

\begin{tabular}{|l|c|c|c|c|c|c|c|c|}
\cline { 2 - 9 } \multicolumn{1}{c|}{} & Days & Block $_{\text {ATL }}$ & Block $_{\text {EUR }}$ & Block $_{\text {total }}$ & Zonal $_{\text {ATL }}$ & Zonal $_{\text {EUR }}$ & Zonal $_{\text {total }}$ & Other \\
\hline BOX $_{\mathbf{N W}}$ & $\mathbf{1 9 0 1}$ & $5.4 \%$ & $8.8 \%$ & $\mathbf{1 4 . 2 \%}$ & $25.9 \%$ & $6.0 \%$ & $\mathbf{3 1 . 9 \%}$ & $\mathbf{5 3 . 9 \%}$ \\
\hline BOX $_{\mathbf{N}}$ & $\mathbf{1 8 4 2}$ & $8.8 \%$ & $8.1 \%$ & $\mathbf{1 6 . 9 \%}$ & $19.3 \%$ & $3.9 \%$ & $\mathbf{2 3 . 2 \%}$ & $\mathbf{5 9 . 8 \%}$ \\
\hline BOX $_{\mathbf{S W}}$ & $\mathbf{1 5 4 2}$ & $17.4 \%$ & $12.9 \%$ & $\mathbf{3 0 . 4 \%}$ & $10.5 \%$ & $4.7 \%$ & $\mathbf{1 5 . 2 \%}$ & $\mathbf{5 4 . 4 \%}$ \\
\hline BOX $_{\mathbf{E}}$ & $\mathbf{1 9 3 3}$ & $15.7 \%$ & $16.2 \%$ & $\mathbf{3 2 . 0 \%}$ & $10.0 \%$ & $2.0 \%$ & $\mathbf{1 2 . 0 \%}$ & $\mathbf{5 5 . 9 \%}$ \\
\hline BOX $_{\mathbf{C}}$ & $\mathbf{1 4 9 8}$ & $11.1 \%$ & $11.0 \%$ & $\mathbf{2 2 . 2 \%}$ & $10.9 \%$ & $5.8 \%$ & $\mathbf{1 6 . 8 \%}$ & $\mathbf{6 1 . 1 \%}$ \\
\hline
\end{tabular}

Table 2 - Confidence levels (bold) after the Anderson-Darling test, the tail parameter, and the scale parameter of each GP fit applied to the tailed distribution (above the $90^{\text {th }}$ percentile) of the $\mathrm{P}_{\mathrm{MAX}}$ series of the five considered boxes of gridpoints, during blocking (left columns) and strong zonal events (right columns) in the ATL and EUR sectors.

\begin{tabular}{|l|c|c|c|c|}
\cline { 2 - 5 } \multicolumn{1}{c|}{$\boldsymbol{P}_{\text {MAX }}$} & Block & Block & Zonal $_{\text {ATL }}$ & ZonaleUR \\
\hline BOX $_{\mathbf{N W}}$ & $\mathbf{9 0 \%} / 0.04 / 19.82$ & $\mathbf{8 5 \%} /-0.18 / 31.71$ & $\mathbf{8 9 \%} /-0.23 / 41.02$ & $\mathbf{9 2 \%} /-0.23 / 41.60$ \\
\hline BOX $_{\mathbf{N}}$ & $\mathbf{9 1 \%} /-0.10 / 25.90$ & $\mathbf{8 8 \%} /-0.19 / 29.42$ & $\mathbf{9 2 \%} /-0.23 / 29.83$ & $\mathbf{9 1 \%} /-0.20 / 27.08$ \\
\hline BOX $_{\mathbf{S W}}$ & $\mathbf{9 1 \%} /-0.18 / 34.06$ & $\mathbf{9 1 \%} /-0.09 / 23.70$ & $\mathbf{8 7 \%} / 0.03 / 21.07$ & $\mathbf{8 7 \%} /-0.32 / 29.15$ \\
\hline BOX $_{\mathbf{E}}$ & $\mathbf{9 1 \%} / 0.00 / 51.24$ & $\mathbf{8 6 \%} /-0.14 / 50.75$ & $\mathbf{9 5 \%} / 0.02 / 47.73$ & $\mathbf{8 8 \%} / 0.02 / 29.33$ \\
\hline BOX $_{\mathbf{C}}$ & $\mathbf{9 2 \%} / 0.04 / 20.99$ & $\mathbf{9 4 \%} / 0.05 / 23.52$ & $\mathbf{8 8 \%} /-0.20 / 29.68$ & $\mathbf{9 1 \%} /-0.13 / 34.98$ \\
\hline
\end{tabular}

Table 3 - Same as Table 2, but for the $\mathrm{P}_{\text {TOт }}$ time series

\begin{tabular}{|l|c|c|c|c|}
\cline { 2 - 5 } \multicolumn{1}{c|}{$\boldsymbol{P}_{\text {Tот }}$} & Block $_{\mathbf{A T L}}$ & BlockEUR $_{\text {E }}$ & Zonal $_{\text {ATL }}$ & ZonalEUR \\
\hline BOX $_{\mathbf{N W}}$ & $\mathbf{9 1 \%} / 0.05 / 90.80$ & $\mathbf{8 8 \%} /-0.10 / 122.36$ & $\mathbf{9 5 \%} /-0.10 / 236.02$ & $\mathbf{9 3 \%} /-0.10 / 236.02$ \\
\hline BOX $_{\mathbf{N}}$ & $\mathbf{8 8 \%} /-0.18 / 135.34$ & $\mathbf{9 3 \%} /-0.16 / 111.37$ & $\mathbf{9 3 \%} /-0.05 / 171.96$ & $\mathbf{9 1 \%} /-0.05 / 171.96$ \\
\hline BOX $_{\mathbf{S W}}$ & $\mathbf{9 1 \%} / 0.04 / 121.87$ & $\mathbf{9 3 \%} /-0.23 / 132.36$ & $\mathbf{9 5 \%} / 0.00 / 98.79$ & $\mathbf{9 4 \%} / 0.00 / 98.79$ \\
\hline BOX $_{\mathbf{E}}$ & $\mathbf{9 4 \%} /-0.07 / 208.26$ & $\mathbf{9 4 \%} /-0.06 / 204.86$ & $\mathbf{9 5 \%} /-0.01 / 167.79$ & $\mathbf{9 4 \%} /-0.01 / 167.79$ \\
\hline BOX $_{\mathbf{C}}$ & $\mathbf{8 9 \%} / 0.02 / 92.55$ & $\mathbf{9 5 \%} /-0.02 / 91.96$ & $\mathbf{9 3 \%} /-0.06 / 107.70$ & $\mathbf{9 1 \%} /-0.06 / 107.70$ \\
\hline
\end{tabular}


